المجلة الدولية للدراسات التربوية والنفسية

بحث رقم 7

المجلد التاسع، العدد الثاني، 468:446

نيسان (2021)

\title{
القيم التنظيمية في المدارس \\ الثانوية الحكومية في مدينة \\ بريدة من وجهة نظر المعلمات
}

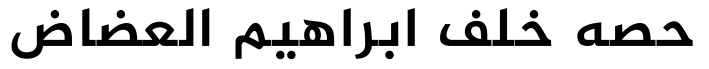 \\ إدارة تربوية_ كلية التربية- جادعة القصيه - السعودية
}

Hussah.khalaf.1996@hotmail.com

قبول البحث: 2020/7/18

مراجعة البحث: 6/22/ 2020

استلام البحث: 2020/6/15

DOI: https://doi.org/10.31559/EPS2021.9.2.7

(a) 10 This file is licensed under a Creative Commons Attribution 4.0 International 


\title{
القيم التنظيمية في المدارس الثانوية الحكومية في مدينة بريدة من وجهة نظر المعلمات
}

\author{
حصها خلف ابراهيم العضاض \\ إدارة تربوية- كلية التربية- جامعة القصييم- المملكة العربية السعودية الراهية \\ Hussah.khalaf.1996@hotmail.com
}

DOI: https://doi.org/10.31559/EPS2021.9.2.7 2020/6/15 2020/6/22 مراجعة البحث: 2020/18: 20بحل البحث:

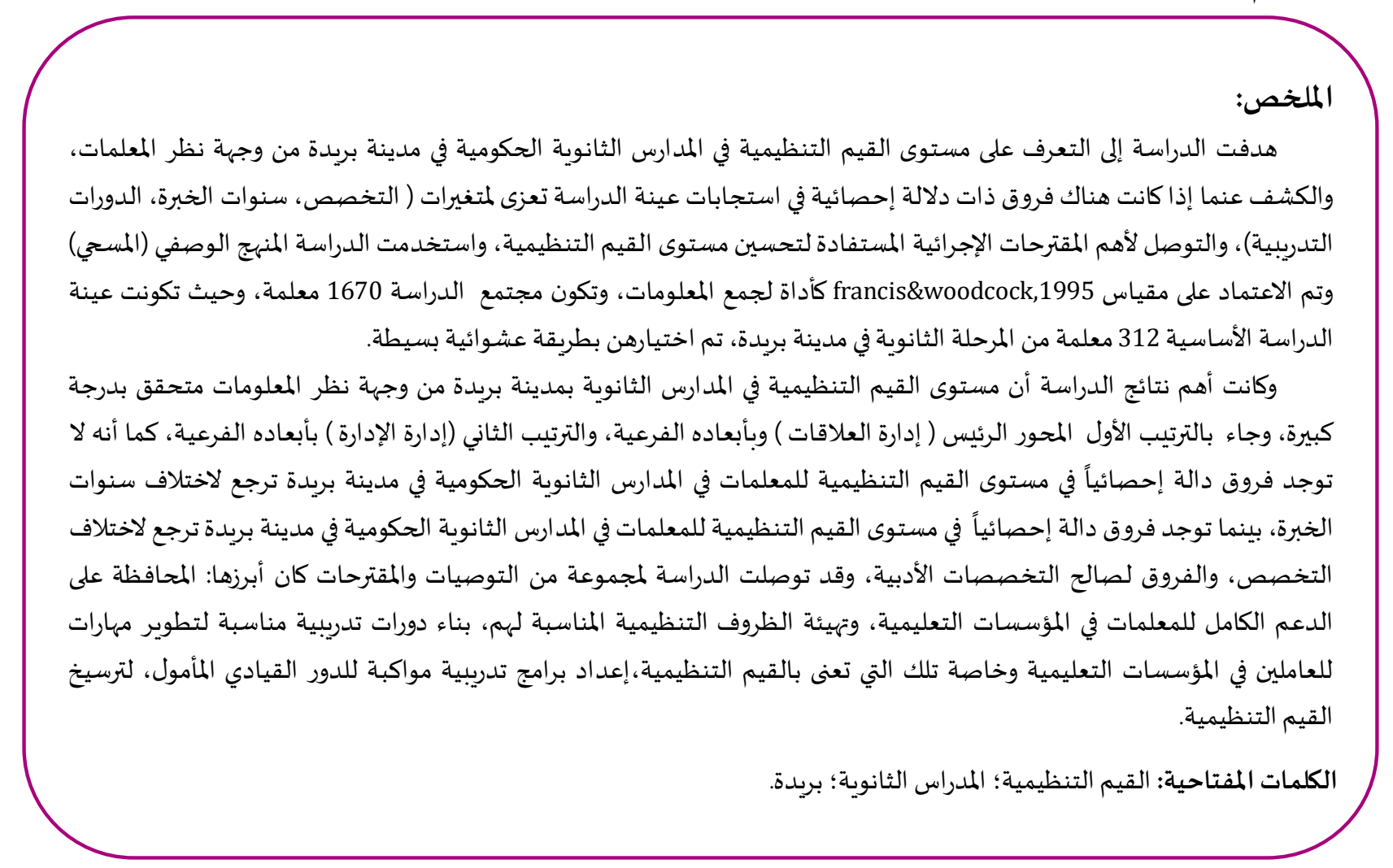

المقدمة:

تمر المملكة العربية السعودية بتطورات وتغيرات لتحقيق رؤية 2030، حيث أولت أهمية كبيرة لتطوير وتعزيز التعليم، وقد رسمت المملكة من

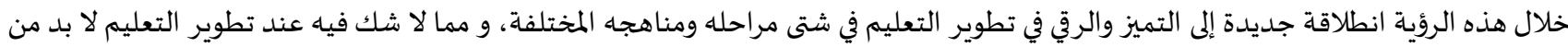

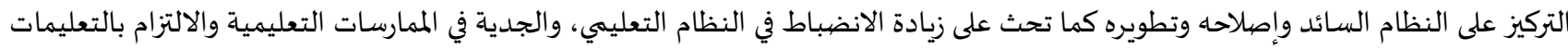

$$
\text { والقواعد التنفيذية. }
$$

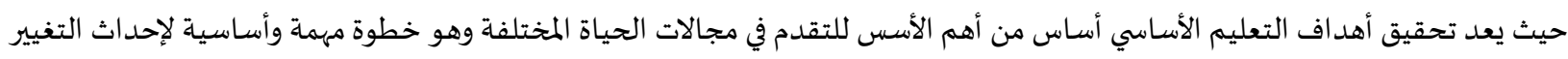

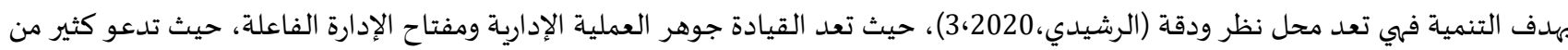

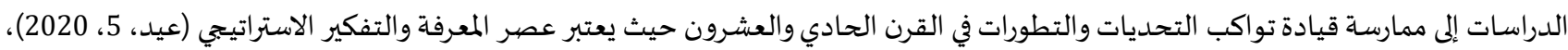

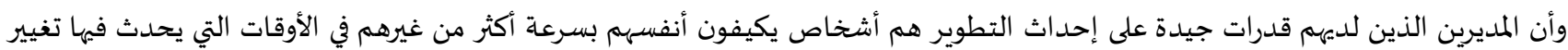

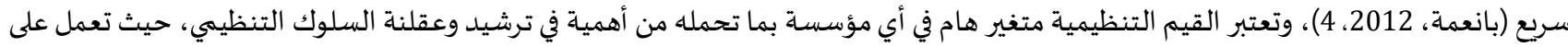


احترام النظام وتحديد المسؤوليات كما تحترم السلطة الرسمية والهيكل التنظيمي وتعمل على تحقيق الطاعة بها، فالقيم التنظيمية جزء لا يتجزأ من

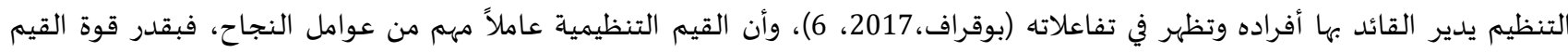

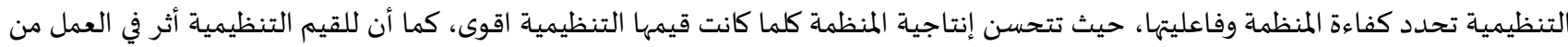

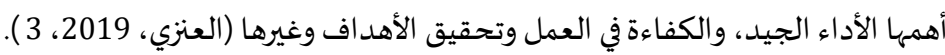

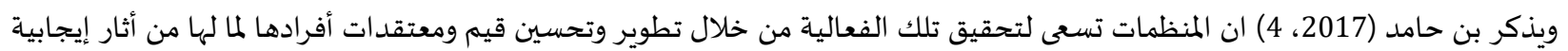
على الفرد والمنظمة في الوقت نفساه وحيث توصل أن القيم التنظيمية تسهم بشكل كبير في جودة التعليم العالي من خلال تفاعل الأساتذة الباحثين

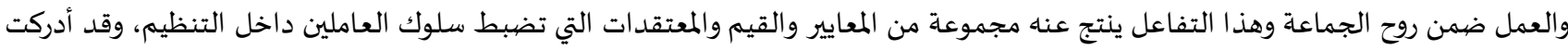

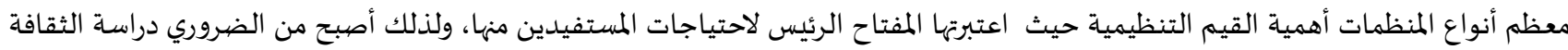

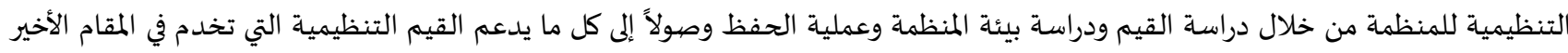

أغراض و أهد اف المنظمة (Bowden,2000,5).

مشكلة الدراسـة:

تعتبر القيم التنظيمية حاجة حقيقية لجميع المنظمات بشتى فروعها واختصاصاتها حيث أنها تؤدي إلى رفع كفاءة المنظمة، حيث يؤكد العنزي (2019، 15) أن القيم التنظيمية عاملاً مهم من عوامل النجاح، فبقدر قوة القيمة القيم التنظيمية تحدد كفاءة المنظمة وفاعليتها، وأظهرت النتائج لمحور

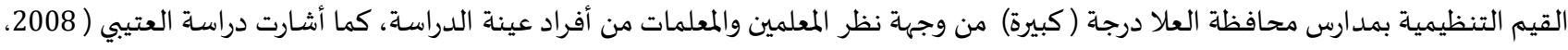

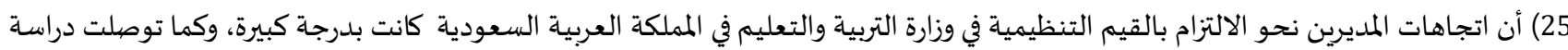

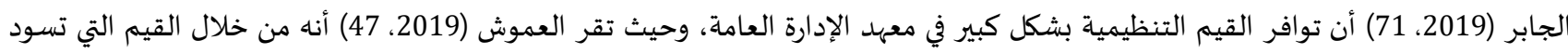

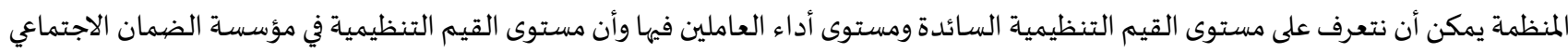
جاءت (متوسطة) من وجهة نظر أفراد العينة، وتوصلت دراسة brendam (2000، 25) أن القيم التنظيمية محققة لدى المقاء المعلمين بدرجة كبيرة، كما

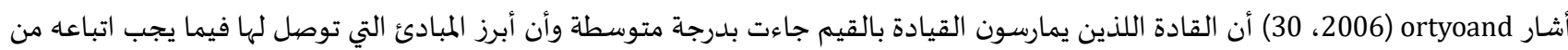

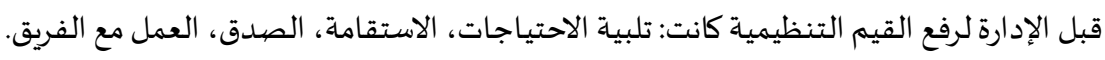

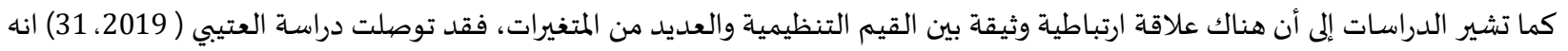

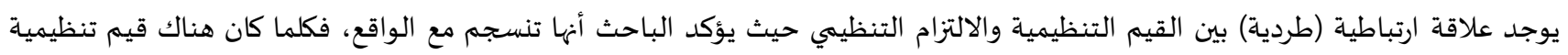
إيجابية يعمل بها المعلمون كلما أدى ذلك إلى التزام المعلمين و انتمائهم للمدارس التي يعملون بها، وحيث يقر العموش (2019، 47) أنها من خلال القيم

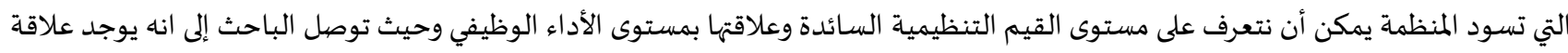
(إيجابية) ما بين القيم التنظيمية وتحسين الأداء، وفي المقابل أوضحت نتائج دراسة الجابر (2019، 72) أنها يوجد علاقة (سلبية) ضيعيفة بئية بين أبعاد

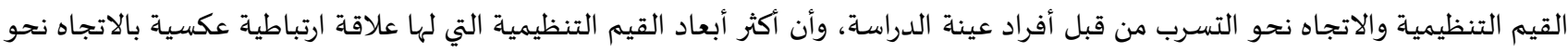

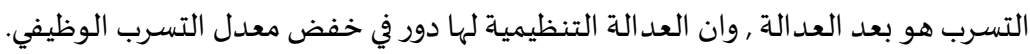
وجاء الغرض من هذه الدراسة لمعرفة القيم التنظيمية السائدة في المدارس الثانوية في مدينة بريدة وذلك بالإجابة على أسئلة الدراسـة.

أسئلة الدراسـة:

1. ما مستوى القيم التنظيمية في المدارس الثانوية الحكومية بمدينة بريدة من وجهة نظر المعلمات؟

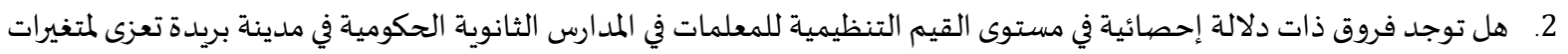

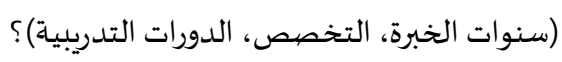

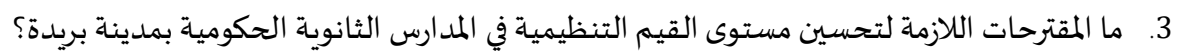

أهداف الدراسة:

1. التعرف على مستوى القيم التنظيمية في المدارس الثانوية الحكومية بمحافظة بريدة من وجهة نظر المعلمات.

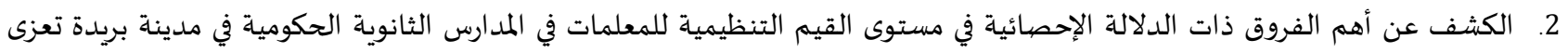

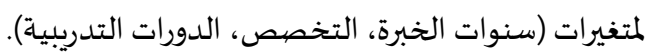

3. وضيع مقترحات لتحسين القيم التنظيمية لدى معلمات المرحلة الثانوية في مدينة بريدة. 
أهمية الدراسة:

1. تأتي أهمية الدراسة من تناولها لموضهوع القيم التنظيمية أحد العوامل المهمة في العملية الإدارية والتعليمية، حيث تعتبر القيم قوة منظمة ومحركة للسلوك

2. تعد هذه الدراسة استكمالاً للجههود المبذولة في مجال (القيم التنظيمية) في المؤسسات التعليمية. 3. أن القيم التنظيمية تقوم بتنمية وعي الموظفين والتزامهم، وتعزيز انتمائهم مما يؤثر إيجابياً على أدائهم. 4. من المأمول أن تزود هذه الدراسة أصحاب القرار في المؤسسـات التعليمية معلومات خاصية عن واقع القيم التنظيمية.

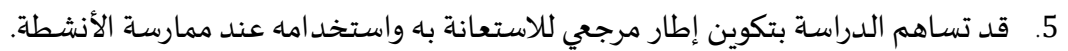

حدود الدراسـة: الحدود الموضيوعية: تناولت هذه الدراسة بعدين رئيسين من أبعاد القيم التنظيمية إدارة الإدارة وتشمل ( القوة، الصفوة، المكافأة ) وإدارة العلاقات وتشمل ( العدل، فرق العمل، القانون والنظام ) تم اختيار هذه الأبعاد بناء على الاتفاق والاطلاع و لمدى ملائمتهن للمجال التربوي. الحدود المكانية: اقتصرت هذه الدراسة المدارس الثانوية الحكومية في مدينة بريدة. الحدود البشرية: معلمات المرحلة الثانوية في المدارس الحكومية في مدينة بريدة.

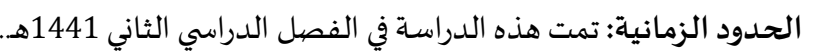

مصططلحات الدراسـة: القيم التنظيمية: يعرفها فر انسيس وودكوك: بأها الاعتقاد الذي تبنى عليه أعمالنا في المنظمات، فهي عبارة عن اختيار الصالح \&oodcock(1995,6) والسيئ، والمهم وغير المهم. عرفها محمود سلمان العلميان(2002، 10) بأهها: " اتفاقات مشتركة بين أعضاء حول ما هو مرغوب أو غير مرغوب في مكان أو بيئة العمل، بحيث

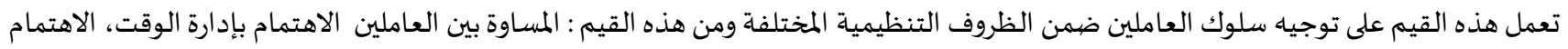

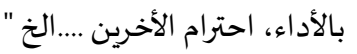
التعريف الإجر ائي للدراسـة: هي القيم والمعتقدات التي يمتلكها المعلم و يلتزم بمضامينها فهي التي تحدد السلوك المقبول والمرفوض، والتي تنعكس على طريقة أدائه وتعمل على الماتل تحديد اتجاهاته وتوجياه سلوكه التنظيمي كما تنعكس القيم التنظيمية على الخصائص الداخلية للمنظمة فهي تحدد الخطوط العريضية لتوجياه السلوك ووضع القرارات وفق أهد اف تسعى إلى تحقيقها بإخلاص وأمانة في المدراس الثانوية الحكومية في مدينة بريدة.

الإطار النظري:

أولاً: مفهوم القيم:

" المعتقدات التي يعتقد أصحابها بقيمتها، ويلتزمون بمضامينها "( القريوتي، 1993, 87)

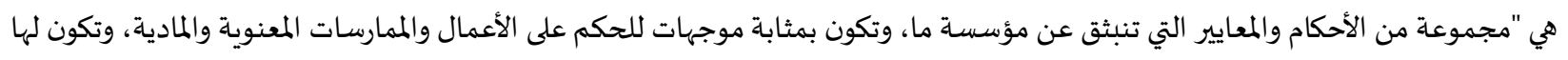

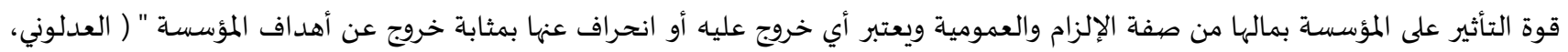

القيمة هي" الحكم الذي يصدره الإنسان على شيء ما مهتدياً بمجموعة المبادئ والمعايير التي وضعها المجتمع الذي يعيش فيه، والذي يحدد

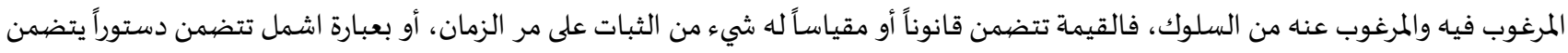

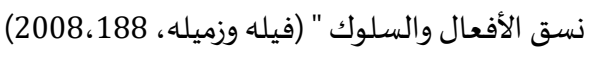
ثانياً: تطور القيم التنظيمية: نمت القيم الإدارية، وتطورت عبر سبع مراحل رئيسية للتطور حيث بات دور المديرين متميزاً مع تطور القيم الإدارية والتنظيمية السائدة، ويمكن

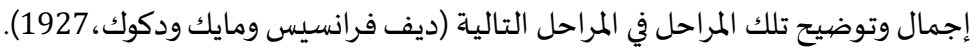

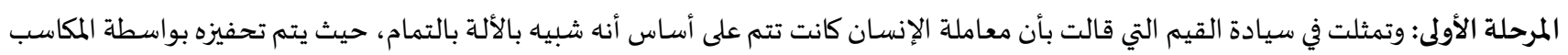

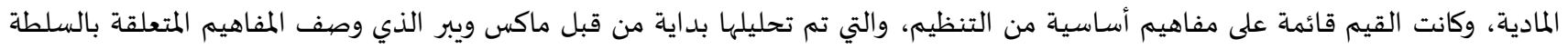


وتدريجها، والأدوار، والإجراءات الرسمية، ثم بدأت المنظمات تنمو وأصبحت معنية بالكفاية، كما عجل التفكير العلمي بالأساس الذي يقوم عليه

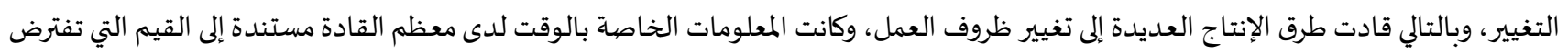

أن الرجال والنساء هم مصيادر مثل مصادر الإنتاج.

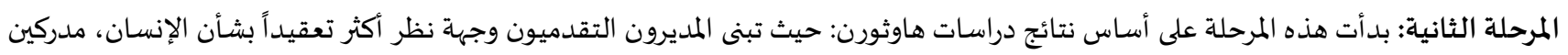

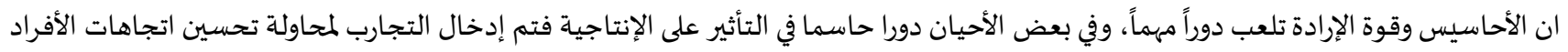

نحو العمل، ومن ثم تدريب المديرين ليصبحوا قادة عمل، كما تم إدخال أساليب تحفيز جديدة إلى إلى بيئة العمل.

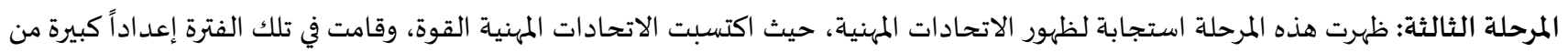

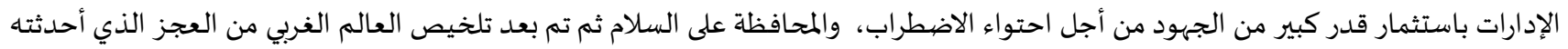

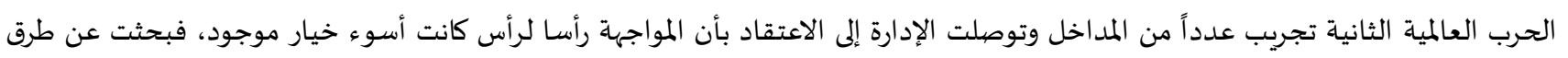

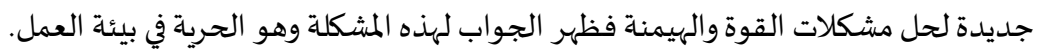

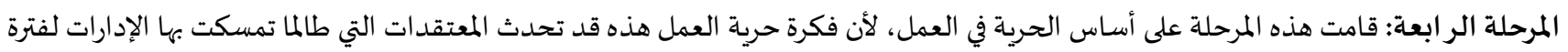

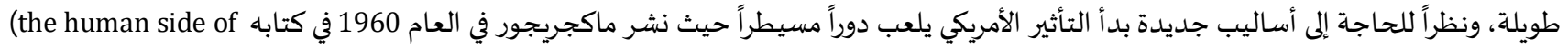
enterprise)

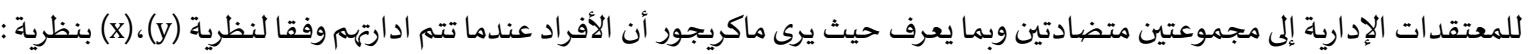

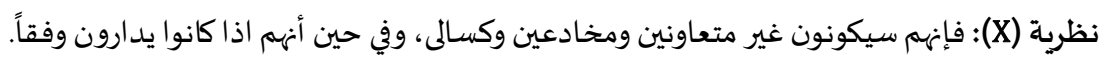

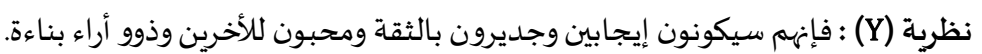

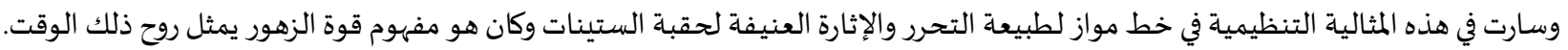

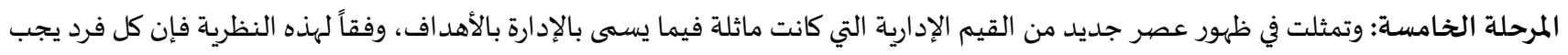
أن يكون لدياء أهداف إنتاجية شـاملة ومتفق عليها، لكي يسمح بالحرية الفردية لتحديد طرق ووسائل إنجاز هذه الأهداف، ولقد كان الهدف بهد من هذه النظرية التوافق بين أهداف المنظمة وأهداف الأفراد.

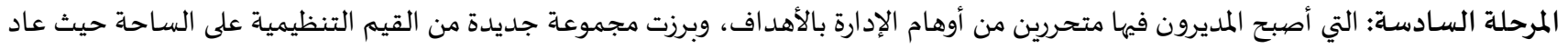

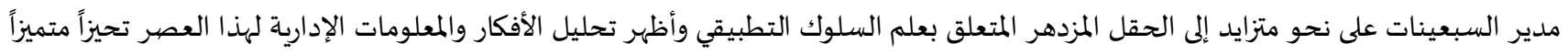

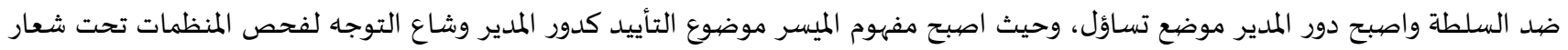
التطوير التنظيمي. المرحلة السابعة: واتسمت بالإثارة لأها كانت تمثل رد فعل أكثر كونها مرحلة تقدمية، وتمثلت في اكتشاف المديرين للدروس التي يعرفها جيداً أجدادهم التنظيمين، حيث بدأت تكتشف من جديد القوة الدافعة لاستغلال الفرص الفردية، والمسئولية الذاتية.

ثالثاً: أهمية القيم التنظيمية: أن القيم هي الأسـاس في أي ثقافة تنظيمية وهي جوهر فلسفة المنظمة لتحقيق النجاح، كما أن القيم شعور بالتوجهات المشتركة لكل العاملين

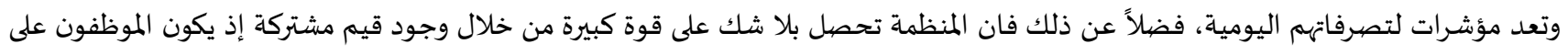

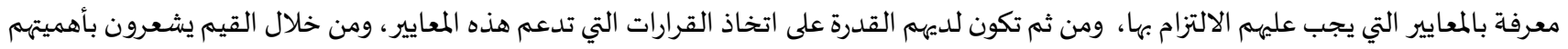

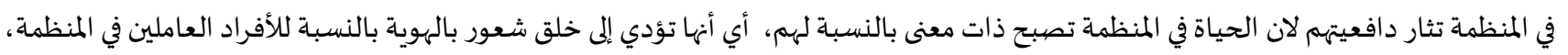
وتصبح القيم حقيقية في عقول عدد كبير منها، إن وجود قيم تنظيمية مشتركة يمتد ليشمل جميع نواحي المنظمة، فالمنظمات التي تمتلك قيما مشتركة

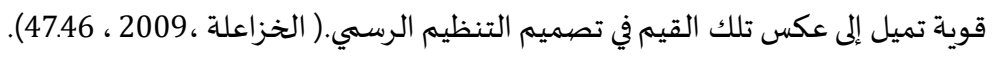

رابعاً: شروط القيم التنظيمية: للقيم التنظيمية العديد من الشروط التي نستطيع متى ما توافرت الحكم على وضوح تلك القيم، وهي على النحو التالي ( ديف فرانسيس ومايك

ودكوك 1995،

اختيار القيم من بين عدة بدائل.

اتساق القيم مع بعضها البعض، فيجب أن تدعم القيم بعضهـا الأخر.

أن تكون معززة لقيم الأداء.

أن تكون قابلة للتوصيل. 
أن تكون جذاباة، وداعية للفخر والاعتزاز. تدوين القيم لتوضيح الصورة العقلية لها، والأثارة النقاش حولها ولضيمان توصيلها برسائل واضحة لإفراد التنظيم.

خامساً: خصيائص القيم التنظيمية:

تتمتع القيم التنظيمية بمجموعة من المميزات والخصيائص والسمات نتطرق إلهها في الآتي:

ه النسبية: تتميز القيم التنظيمية بالنسبية وذلك لاختلافها بين الأفراد العاملين على اختلاف رغباتهم وظروفهم، أي أن لكل فرد عامل مجموعاة من

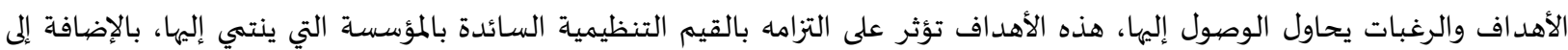

$$
\text { الظروف البيئية التي تسود هذه المؤسسـة. }
$$

ذات طبيعة عامة (عمومية): أي أهها تكون في الوسط التنظيمي ككل وتمس جميع الموارد المادية والمالية بالإضافة إلى الموارد البشرية، التي تعتبر

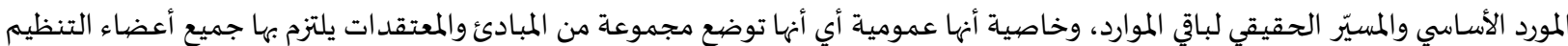

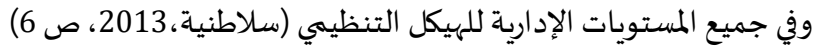
تجريدية: أي أن القيم معان مجردة تتسم بالموضيوعية والاستقلالية تنعكس معانيها الحقيقية في سلوك الأفراد العاملين وفي الظروف البيئية التي

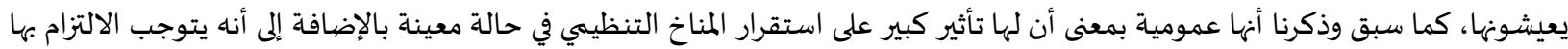
من جميع العاملين بنفس الدرجة، أي بمعنى لا يكون هناك عامل يخضع لقيمة تنظيمية معينة ويتغاضى على قئى قيمة أخرى (العميان، 2002،

متدرجة: ويقصد بها كل عامل تتشكل لديه القيم التنظيمية على شكل تدرج هرمي (من المهم إلى الأهم)، وهذا يتحدد من خلال ضرورة التزامه

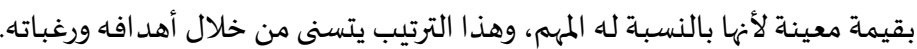
مكتسية: أي أهها ليست فطرية وكما أن الفرد العامل عند دخوله المؤسسة لأول مرة يكون خالياً أو فارغاً من القيم التنظيمية ويبدأ اكتسابها طيلة فترة مزاولته العمل فيها، وبما أنها مكتسبة وتنعكس على السلوك الفردي داخل المؤسساة، فإنها بذلك تكون قابلة للقياس والتقييم حيث

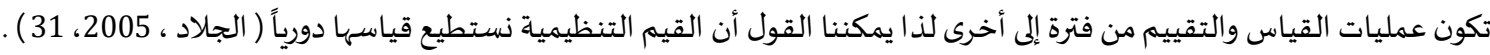
سادساً: تصنيفات القيم التنظيمية:

أولاً : تصنيف ديف فر انسيس ومايك ودكوك (Dave Francis \& Mike Woodcock) الذين أشاروا إلى أنه ولكي تكون المنظمة ناجحة في عالم اليوم، فإنها يجب عليها القيام بأربع قضايا رئيسية تقود إلى اثنتي عشرة قضية فرعية والتي تشتق الاثنتا عشرة قيمة كالتالي: القضية الأولى: إدارة الإدارة:

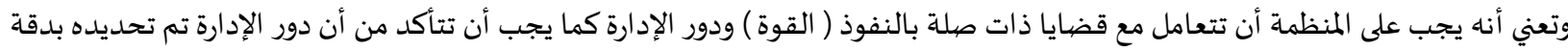
ووضوح، وبناء على هذه القضية الجوهرة فإن القضايا الفرعية ينبغي تقديمها كما يلي : القوة (النفوذ ): وتتمثل في امتلاك المجموعة الإدارية لنظم المعلومات والسلطة والمركز الوظيفي التي تمكنها من تقرير مهمة المنظمة، والمصهادر

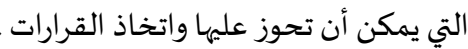
الصفوة: فالمنظمة الناجحة تدرك أهمية الحصبول على أفضل المرشحين المحتملين في الأعمال الإدارية. المكافأة: فالمنظمة الناجحة هي التي تحدد الناجح وتكافئ علياء.

القضية الثانية: إدارة المهمة:

وتعني أنه يجب على المنظمة أن تتعامل مع قضايا ذات صلة بأداء العمل، والكيفية التي تحقق بها المنظمة أهدافها، وبناء على هذه القضية الجوهرة فإن القضايا الفرعية ينبغي تقديمها كما يلي:

الفعالية: فالتركيز على القضايا الصحيحة يجب أن يكون مطرداً، والمنظمة الناجحة قادرة على تركيز مصادرها على الأنشطة التي تعود عليها بأفضل النتائج الكفاية: وقد قيل أن الإدارة الجيدة والكفؤة هي تلك التي تستطيع أن تعمل مئات الأشياء الصغيرة بطريقة متقنة. الاقتصاد: وكما هو معلوم فإن انفاق النقود أسهل من جمعها، لذا فإن غياب الرقابة على التكاليف يعد سبباً رئيسياً في فشل الكثير من الأعمال . القضية الثالثة: إدارة العلاقات: وتعني أنه يجب على المنظمة أن تتعامل مع قضايا ذات صلة، بالحصول على أفضل إسهام من موظفيها، وبناء على هذه القضية الجوهرة فإن

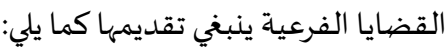


العدل: حيث يتضح تأثير الإدارات بتصرفها في حياة الفرد، سواء أكان ذلك في العمل أو خارج العمل، ذلك أن ما يفعله المديرون وما لا يفعلونه له تأثير كبير على نوعية حياة كل الموظفين.

العمل الجامعي ( فرق العمل ): فالجماعة المنظمة جيدا والمحفزة تستطيع أن تنجز أكثر من مجرد مجموعة أفراد الذين يشكلون الجماعة . القانون والنظام: حيث يتعين على كل جماعة أن تطور إطاراً من القوانين التي تنظم تصرفاتها .

القضية الر ابعة إدارة البيئة:

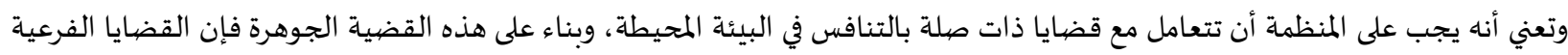

ينبغي تقديمها كما يلي:

الدفاع: حيث تقع الكثير من المنظمات التجارية تحت وطأة المنافسة مع المنظمات الأخرى، والمنظمة الناجحة هي التي تقوم بدراسـة التهديدات

الخارجية ثم تضع بعد ذلك خطة دفاعية قوية .

التنافس: فالقدرة عل أن تكون منافسا هي الطريقة الوحيدة الموثوق بها للبقاء.

استغلال الفرص: فرغم وجود أفضل الخطط الرائعة المحكمة، فإنه من المحتم أن هناك فرصاً وتهديدات سوف تحدث، ولا يمكن للمنظمات أن تتجاهل الأمور الفجائية، وبالتالي فإنه من الحكمة العلمية أن تبحث هذه المنظمات الفمات عن فرص في الخارج بدلاً من أن تعطي مجالاً للأخرين لينتزعوا

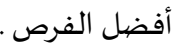

ثانياً: تصنيف كوين ورو باخ الذي صنف القيم التنظيمية في أربعة قيم هي ( التويجر ،2003، 22) 1 2. 2 ت قيم العلاقات الإنسانية. 3. ق قيم النظام المفتوح.

4. - ت قيم العمليات الداخلية .

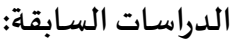

دراسة العنزي (2019): هدفت الدراسة إلى التعرف على القيم التنظيمية بمدارس محافظة العلا وعلاقتها بالصراع التنظيمي لدى المعلمين

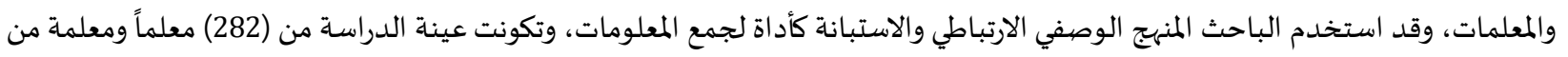
مدارس محافظة العلا ـوأظهرت النتائج لمحور القيم التنظيمية بمدارس محافظة العلا درجة ( كبيرة) بمتوسط من وجهة نظر المعلمين والمعلمات من أفراد عينة الدراسة والعلاقة وأيضاً توجد علاقة عكسية قوية بين توافر القيم التنظيمية ومستوى الصراع التنظيمي حيث كلما توافرت

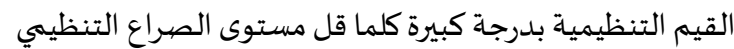
دراسة العموش (2019): هدفت الدراسة التعرف على اثر القيم التنظيمية في تحسن أداء العاملين في مؤسسة الضمان الاجتماعي الأردنية، وقد

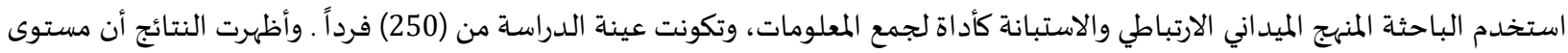
القيم التنظيمية في مؤسسة الضمان الاجتماعي جاءت متوسطة من وجهة نظر أفراد العينة، ووجود اثر إيجابي ما بين القيم التنظيمية وتحسين الأداء.

دراسة العتيبي (2019): هدفت الدراسة التعرف على القيم التنظيمية في المدارس الثانوية الحكومية بمحافظة الطائف وعلاقتها بالالتزام التنظيمي للمعلمين، وقد استخدم الباحث المنهج الوصفي الارتباطي والاستبانة كأداة لجمع المعلومات، وأظهرت النتائج أن مدى توافر القيم التنظيمية في المدارس الثانوية الحكومية بمحافظة الطائف جاء بدرجة (عالية) من وجهة نظر المعلمين وحيث يؤكد الباحث على وجود علاقية

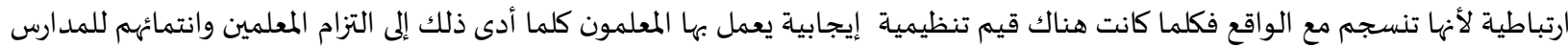
التي يعملون بها.

دراسة الجابر (2019): هدفت الدراسة تحديد القيم التنظيمية وعلاقتها بالتسرب الوظيفي من وجهة نظر أعضاء هيئة التدريب بعهد الإدارة العامة، وقد استخدمت الباحثة المنهج الوصفي المستي والاستبانة كأداة لجمع المعلومات، وتكونت عينة الدراسة من (75) عضيواً، وأظهرت

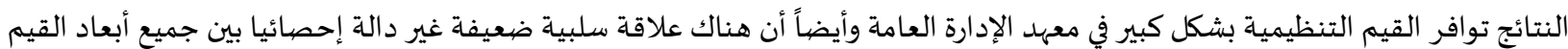
التنظيمية والاتجاه نحو التسرب الوظيفي من قبل أفراد عينة. هunter (2019) (20r) هدفت الدراسة التعرف على القيم الشخصية وعلاقتها بالقيم التنظيمية لدى المديرات في الجامعات العامة للبحث، حيث

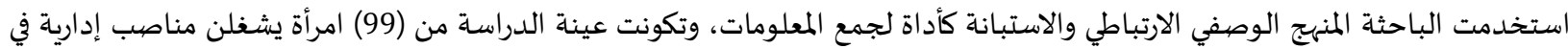
التعليم العالي. وأظهرت النتائج أن القيم جاءت بدرئه بلدرجة متوسطة . 
دراسة الرحومي (2018): هدفت الدراسة التعرف على استخدام وسائل التواصل الاجتماعي في نشر القيم التنظيمية واثرها على تحسين أداء

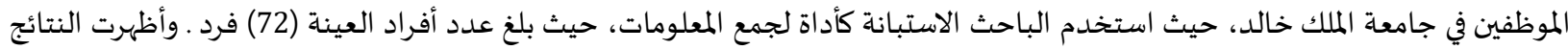

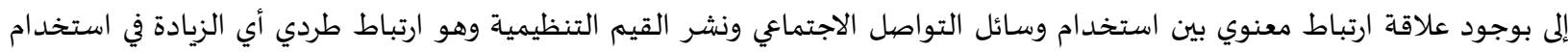
وسائل التواصل الاجتماعي يؤدي إلى زيادة في نشر القيم التنظيمية بين القيم وتحسين الأداء.

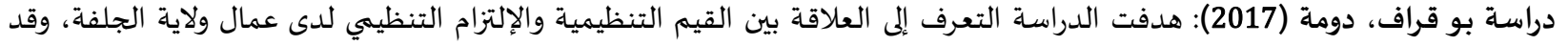

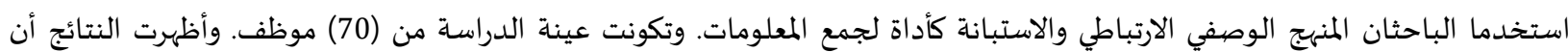
مستوى القيم التنظيمية لدى عمال ولاية الجلفة جاء منخفض، ووجود علاقة ارتباطية موجبة بين القيم التنظيمية والالتزام التنظيمي. دراسة بانعمة (2012): هدفت الدراسة التعرف على القيم التنظيمية المحفزة للإبداع الإداري لدى مديرات مدارس التعليم الثانوي العام

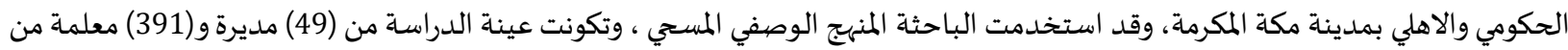

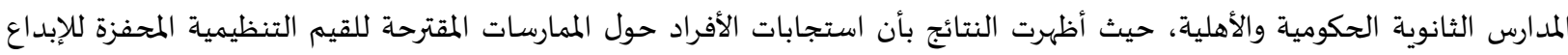
الإداري كانت عالية جداً.

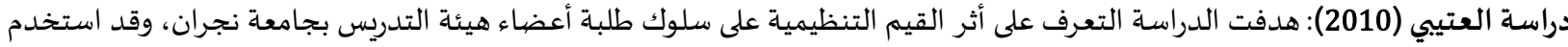

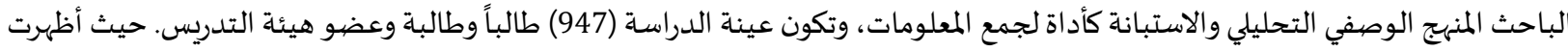
النتائج أن القيم التنظيمية تتوافر لدى الطلبة وأعضاء هيئة التدريس من وجهة نظرهم بدرجة متوسطة.

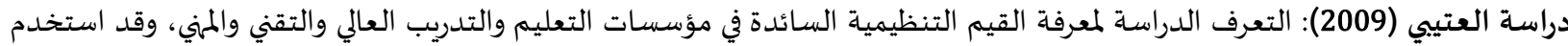

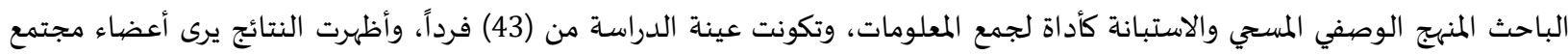

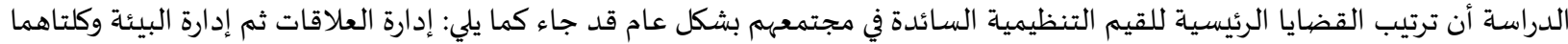

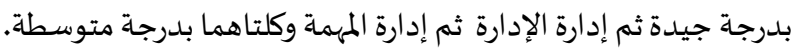
دراسة العتيبي (2008): هدفت الدراسة التعرف على اتجاهات المديرين نحو الالتزام بالقيم التنظيمية في وزارة التربية والتعليم في المملكة العربية العربية

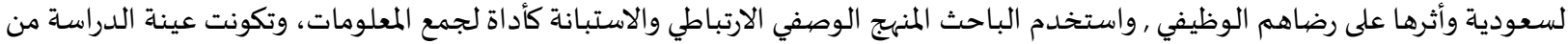

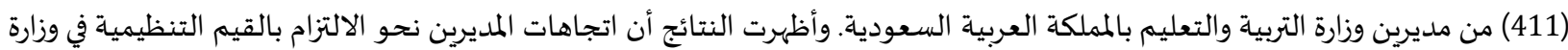
التربية والتعليم كانت إيجابية • Ortyoand (2006) هدفت الدراسة التعرف للكشف عن العلاقة بين سلوك القيادة والقيم التي يعتنقها القائد في كليات التربية والاقتصاد في

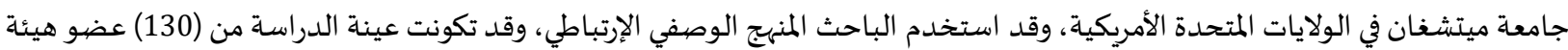
تدربس وإداري، وأظهرت النتائج أن القادة في جامعة ميتشغان يمارسون نمط القيادة بالقيم بدرجة متوسطة.

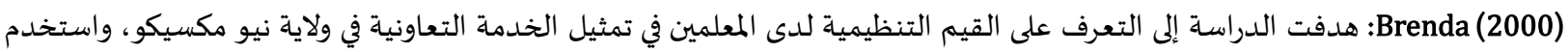
الباحث المنهج الوصفي الارتباطي والاستبانة كأداة لجمع المعلومات، وتكونت عينة الدراسة من (201) فرد. وأظهرت النتائج أن 14 قيمة من القيم

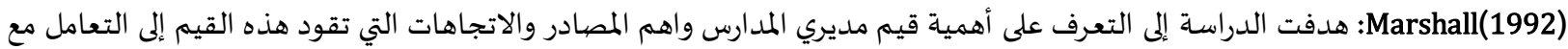

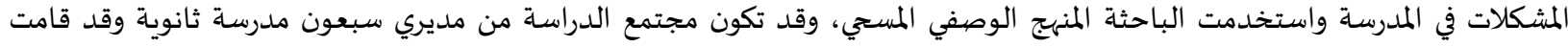

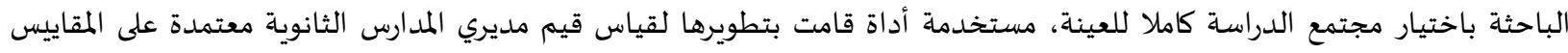
الخاصة بالقيم، وأظهرت النتائج أن القيم لدى المدراء جاءت الماءت بدرجة كبيرة. التعقيب على الدراسات السابقة: أوجه التشابه بين الدراسة الحالية والدراسات السابقة: • المنهج: تتفق الدراسة الحالية مع أغلب الدراسات في المنهج الوصفي وتتفق مع كل من دراسة: بانعمة (2012)، العتيبي (2009)، Yilmaz\&balci) (2007)، (1992) في المنهج الوصفي المستي. • العينة: اتفقت عينة الدراسة الحالية في استهدافها لمجتمع المعلمين أو المعلمات كعينة للدراسة مع كل من دراسة: العنزي (2019)، العتيبي

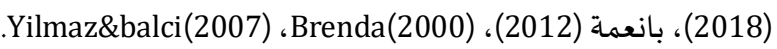
الأداة: تتفق الدراسة الحالية مع أغلب الدراسات في استخدام الاستبانة أداة لجمع البيانات. 
أوجه الاختلاف بين الدراسة الحالية والدراسـات السـابقة:

•المنهج: اختلف منهج الدراسـة الحالية مع منهج كل من دراسة: العنزي (2019)، العتيبي (2019)، الجابر (2019)، (2019)hunen)، العنزي

(2018)، بوقراف و دومة (2017)، عياد(2015)، العتيبي (2008).

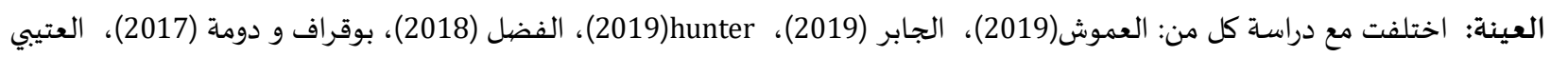

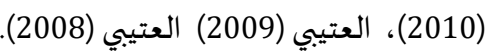

• الحدود المكانية: اختلفت الدراسة الحالية عن الدراسات السابقة من حيث مكان تطبيق الدراسة.

أوجه الاستفادة من الدراسات السابقة في الدراسة الحالية:

في تحديد الإطار العام للدراسـة.

هاعدت الدراسات السابقة في تحديد مشكلة البحث وصياغتها من خلال دعمها بالنتائج.

تم الاستفادة من الدراسات السابقة في بناء أداة الدراسـة.

ساعدت الدراسات السابقة في تحديد أهمية وأهداف الدراسـة.

استفادت الدراسـة الحالية من الدراسات السابقة في بناء الإطار النظري للدراسة.

الاستفادة من نتائج الدراسات السابقة في تفسير نتائج الدراسـة الحالية.

منهجية الدراسـة وإجراءاتها:

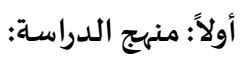

في الدراسة الحالية تم استخدام المنهج الوصفي المستي وذلك للإجابة عن أسئلة البحث الحالي وهو المنهج المناسب لمثل هذا البحث الحالي.

ثانياً: مجتمع الدراسة:

تمثل مجتمع الدراسـة في الدراسة الحالية في جميع معلمات المدارس الثانوية الحكومية في مدينة بريدة بمنطقة القصيم بالمملكة العربية

السعودية، في الفصل الدراسي الثاني من العام الدراسي 1441هـ، والبالغ عددهن 1670وفق أخر إحصائية لوزارة التعليم (وزارة التعليم ، 2020)

ثالثاً: عينة الدراسة:

1. عينة تقنين الاستبانة (العينة الاستطلاعية):

تكونت العينة الاستطلاعية التي تم التأكد من صدق وثبات الاستبانة المستخدمة في البحث الحالي بالتطبيق عليها من 45 معلمة من معلمات

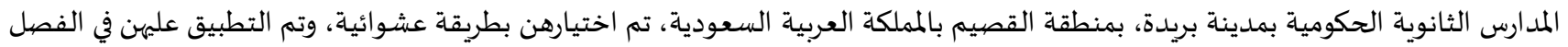
الدراسي الثاني من العام الدراسي 1441 14هـهـ

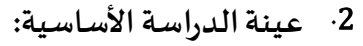

تكونت عينة الدراسة الأساسية من 312 معلمة من معلمات المدارس الثانوية الحكومية بمدينة بريدة بمنطقة القصيم بالمملكة العربية السعودياة، تم اختيارهن بطريقة عشوائية بسيطة من غير المشاركين في الدراسة الاستطلاعية، وتم التطبيق عليهن في الفصل الدراسي الثاني من العام

الدراسي 1441 هـ.

والجدول التالي يوضح توزيع أفراد عينة الدراسة في ضوء المتغيرات المختلفة:

جدول (1): توزيع أفراد عينة الدراسة الأساسية في ضوء المتغيرات المختلفة

\begin{tabular}{|c|c|c|}
\hline النسبة الن & 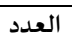 & سنوات الخبرة \\
\hline$\% 19.2$ & 60 & أقل من 5 سنوات \\
\hline$\% 22.5$ & 70 & من 5 سنوات إلى أقل من 10 سنوات \\
\hline$\% 58.3$ & 182 & من 10 سنوات فاكثر \\
\hline 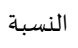 & 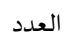 & التخصص \\
\hline$\% 63.1$ & 197 & أدبي \\
\hline$\% 36.9$ & 115 & 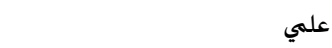 \\
\hline النسبة & 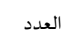 & الدورات التدريبية \\
\hline$\% 13.1$ & 41 & لم احضر أي دورة تدريبية \\
\hline$\% 28.6$ & 89 & حضرت من دورة إلى ثلاث دورات \\
\hline$\% 58.3$ & 182 & حضرت أكثر من ثلاث دورات \\
\hline
\end{tabular}


يتضح من الجدول السابق أن النسبة الأكبر من المعلمات عينة البحث الأساسية كن من أصحاب سنوات الخبرة من 10 سنوات فأكثر بنسبة

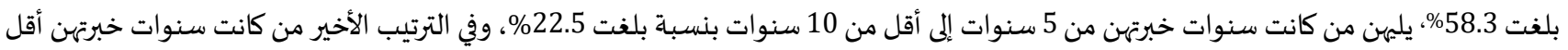
من 5 سنوات بنسبة بلغت 19.2\% رابعاً: أدوات الدراسة: لإلممع البيانات اللازمة للإجابة عن أسئلة البحث الحالي وتحقيقه للأهداف التي يسعى إليها تم استخدام مقياس(francis \& woodcock1995)

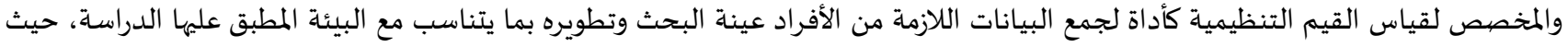

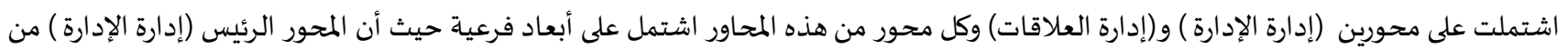

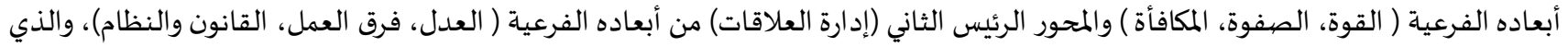
يتكون من 30 عبارة موزعة على تلك الأبعاد تقيس القيم التنظيمية.

للتحقق من صدق الاستبانة الحالية تم الاعتماد على الصدلق الظاهري (صدق المحكمين) Face Validity حيث تم عرض الاستبانة على اثنين من

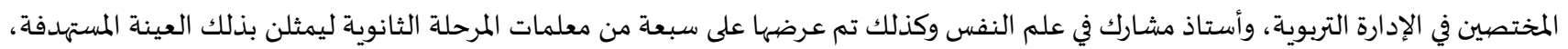

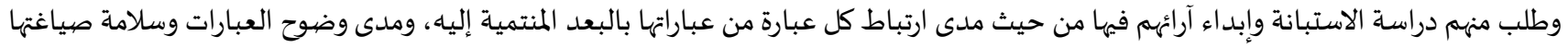

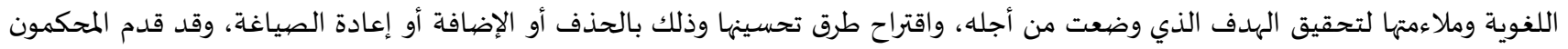

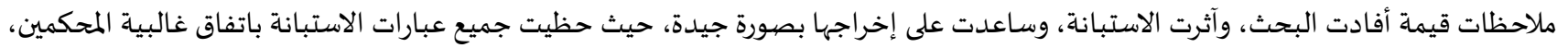

مع بعض الملاحظات التي تم مراعاتها في النسخة النهائية من الاستبانة.

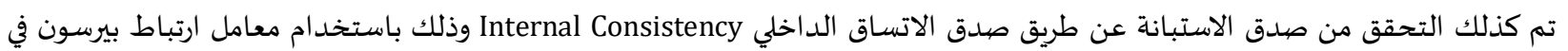

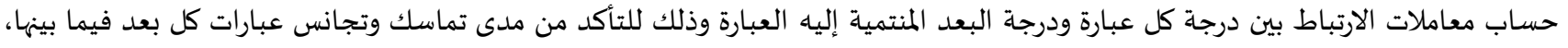

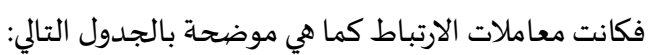
جدول (2): معاملات الارتباط بين درجات عبارات الاستبانة والدرجة الكلية للبعد المنتمية إليه العبارة

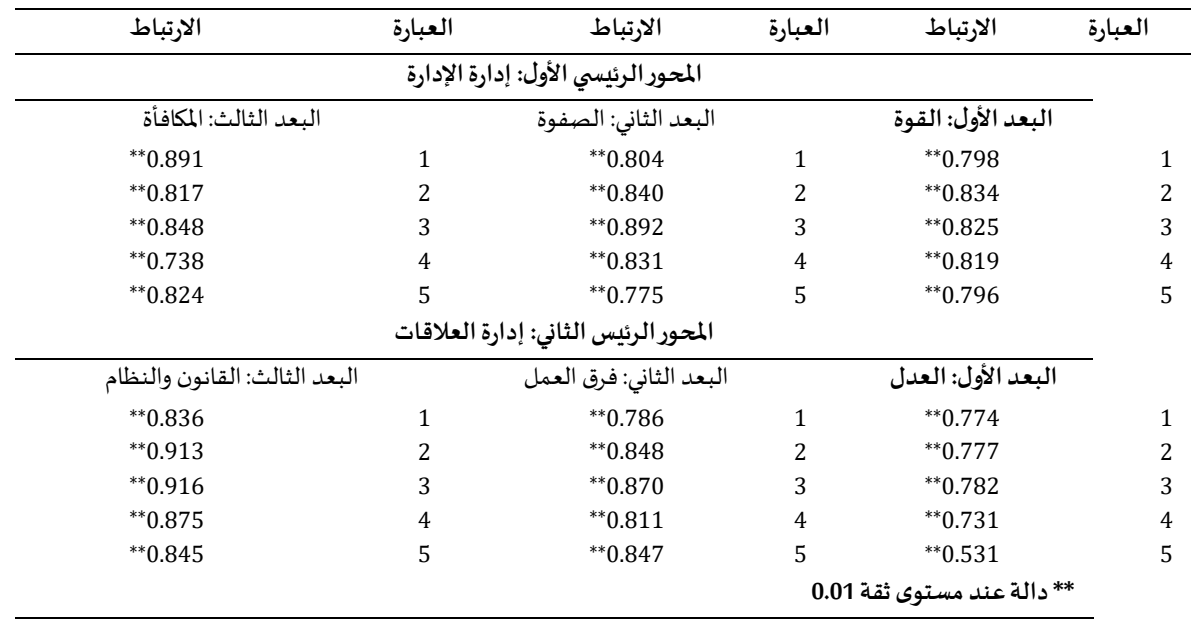

تضح من الجدول السابق أن معاملات الارتباط بين درجات عبارات الاستبانة والدرجة الكلية للبعد المنتمية إليه العبارة جميعها معاملات المبات ارتباط

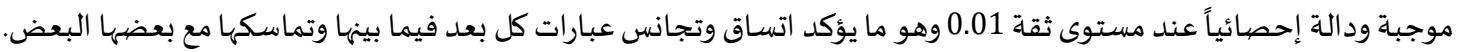

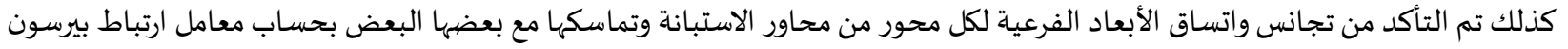

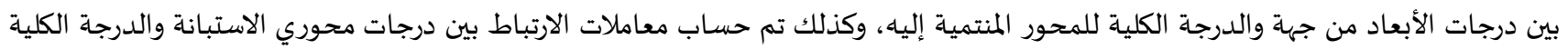

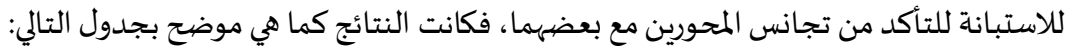


جدول (3): معاملات الارتباط بين درجات أبعاد ومحاور الاستبانة والدرجة الكلية

\begin{tabular}{|c|c|c|c|c|}
\hline \multirow{2}{*}{ ثلاستبانة ارتباط المحور بالدرجة الكلية } & \multicolumn{3}{|r|}{ 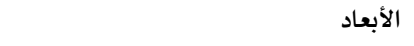 } & 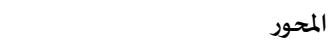 \\
\hline & المكافأة & الصفوة & 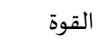 & المحور الرئيسي الأول: إدارة الإدارة \\
\hline${ }^{* *} 0.954$ & ${ }^{* *} 0.899$ & ${ }^{* *} 0.917$ & ${ }^{* *} 0.8568$ & معامل ارتباط البعد بالمحور \\
\hline معامل ارتباط المحور بالدرجة الكلية & القانون والنظام & فرق العمل & 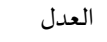 & المحور الرئيس الثاني: إدارة العلاقات \\
\hline ل للاستبانة & & & & \\
\hline${ }^{* *} 0.948$ & $* * 0.928$ & ** 0.916 & **0.815 & معامل ارتباط البعد بالمححور \\
\hline
\end{tabular}

يتضح من الجدول السابق أن معاملات الارتباط بين درجات الأبعاد الفرعية للاستبانة والدرجة الكلية للمحور المنتمي إليه البعد وكذلك معاملات

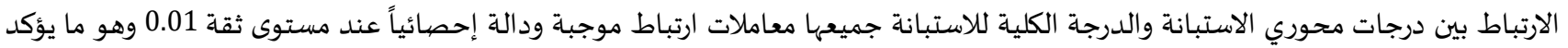
اتساق وتجانس الأبعاد والمحاور فيما بينها وتماسكها مع بعضها لبها البعض. ثانياً: الثبات: تم التحقق من ثبات درجات الاستبانة الحالية وأبعادها ومحاورها الفرعية باستخدام معامل ثبات ألفا كرونباخ فكانت معاملات الثبات كما هو موضح بالجدول التالي:

\begin{tabular}{|c|c|c|}
\hline معامل ثبات ألفا كرونباخ & الأبعاد & المحور \\
\hline 0.939 & القوة & المحور الرئيسي الأول: إدارة الإدارة \\
\hline 0.890 & الصفوة & \\
\hline 0.891 & 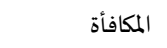 & \\
\hline 0.945 & ثبات المحور ككل & \\
\hline 0.840 & 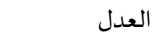 & المحور الرئيس الثاني: إدارة العلاقات \\
\hline 0.880 & فرق العمل & \\
\hline 0.954 & 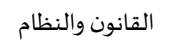 & \\
\hline 0.934 & ثبات المحور ككل & \\
\hline 0.964 & & الثبات العام للاستبانة (الاستبانة ك \\
\hline
\end{tabular}

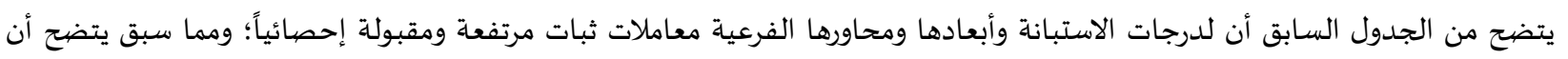

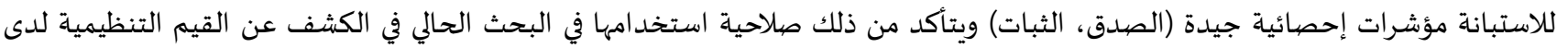
معلمات المدارس الثانوية الحكومية في مدينة بريدة. ويتب ملاحظة أنه تتم الاستجابة لعبارات الاستبانة المستخدمة في البحث الحالي بأن يتم الاختيار ما بين خمسة اختيارات، تتمثل في (صحيحة

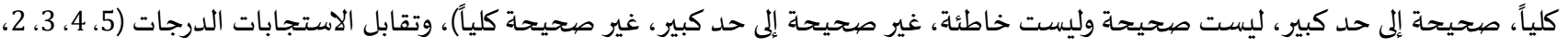

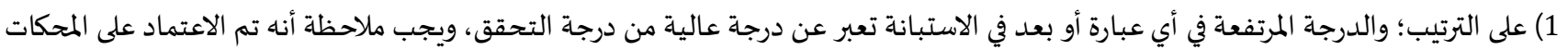
التالية في الحكم على القيم التنظيمية لدى معلمات المدارس الثانوية الحكومية في مدينة بريدة، بناءً على المتوسطات الحسابية للعبارات والمتوسطات

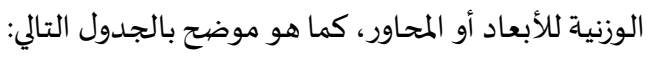

\begin{tabular}{|c|c|}
\hline درجة التحقق & المتوسط الحسابي للعبارة أو المتوسط الوزني للبعد \\
\hline 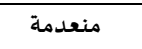 & أقل من 1.8 \\
\hline 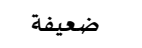 & من 1.8 إلى أقل من 2.6 \\
\hline متوسطة & من 2.6 إلى أقل من 3.4 \\
\hline 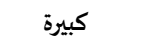 & من 3.4 إلى أقل من 4.2 \\
\hline كبيرة جداً & من 4.2 فأكثر \\
\hline
\end{tabular}

خامساً: الأساليب الإحصبائية المستخدمة: في البحث الحالي تم استخدام العديد من الأساليب الإحصائية باستخدام الحزمة الإحصائية في العلوم الاجتماعية SPSS كالتالي:

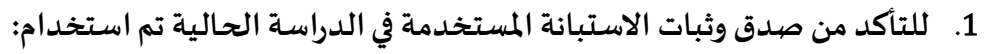
معامل ارتباط بيرسون Pearson Correlation في التأكد من صدق الاتساق الداخلي للاستبانة. 
معامل ثبات ألفا كرونباخ Alpha Cronbach في التأكد من ثبات الاستبانة.

2. لإجابة عن أسئلة الدراسة تم استخدام:

التكرارات Prequencies والنسب المئوية Percent والمتوسطات Mean والانحرافات المعيارية Std. Deviation في الكشف عن مستوى القيم

التنظيمية لدى معلمات المدارس الثانوية الحكومية في مدينة بريدة.

اختبار "ت" للمجموعات المستقلة Independent Samples T-Test في التعرف على مدى اختلاف استجابات أفراد عينة البحث حول القيم

التنظيمية لدى معلمات المدارس الثانوية الحكومية في مدينة بريدة والتي ترجع لاختلاف متغير (التخصص). اختبار تحليل التباين أحادي الاتجاه One Way ANOVA في التعرف على مدى اختلاف استجابات أفراد عينة البحث حول القيم التنظيمية لدى مئس

معلمات المدارس الثانوية الحكومية في مدينة بريدة والتي ترجع لاختلاف متغيري (سنوات الخبرة، الدورات التدربيية).

نتائج الدراسة ومناقشتها:

أولاً: نتائج إجابة السؤال الأول: ينص السؤال الأول الدراسة الحالية على "ما مستوى القيم التنظيمية في المدارس الثانوية الحكومية في مدينة

بريدة من وجهة نظر المعلمات ؟ أبهات

للإجابة عن هذا السؤال تم حساب التكرارات والنسب المئوية لاستجابات أفراد عينة البحث على كل عبارة من عبارات الاستبانة والمتعلقة بمستوى القيم التنظيمية لدى معلمات المدارس الثانوية الحكومية في مدينة بريدة، ثم تم حساب المتوسطات والانحرافات المعيارية لهذه الاستجابات وذلك لتحديد درجة تحقق كل عبارة من هذه العبارات، فكانت النتائج كما هي موضحة فئه في التالي:

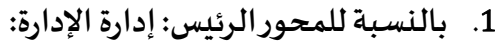

البعد الأول: القوة:

جدول (6): التكرارات والنسب المئوية والمتوسطات والانحر افات المعيارية لاستجابات عينة الدراسة حول مستوى القيم التنظيمية في المدارس الثانوية

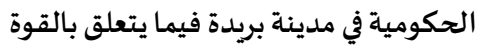

\begin{tabular}{|c|c|c|c|c|c|c|c|c|c|c|c|c|c|c|c|}
\hline \multirow[t]{5}{*}{ الترتيب } & \multirow{5}{*}{ دالتحقق } & \multirow{5}{*}{ المعياري } & \multirow[t]{5}{*}{ المتوسط } & & & & & & & & & \multicolumn{2}{|c|}{ الاستجابة } & \multirow[t]{5}{*}{ العبارات } & \multirow[t]{5}{*}{ 5 } \\
\hline & & & & \multirow{2}{*}{\multicolumn{2}{|c|}{ صحيحة كلياً }} & \multirow{2}{*}{\multicolumn{2}{|c|}{ حد كييرة إلى }} & & 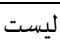 & \multirow{2}{*}{\multicolumn{2}{|c|}{ غدير صحيح }} & \multicolumn{2}{|c|}{ غير صحيح } & & \\
\hline & & & & & & & & & صحيح | (1) & & & & كلياً & & \\
\hline & & & & \multicolumn{10}{|c|}{ وليست خاطئة } & & \\
\hline & & & & نسبة & تكرار & نسبة & تكرار & نسبة & تكرار & نسبة & تكرار & نسبة & تكرار & & \\
\hline \multirow[t]{3}{*}{3} & كبيرة & 0.799 & 4.109 & 29.5 & 92 & 59.0 & 184 & 5.8 & 18 & 4.5 & 14 & 1.3 & 4 & تتصرف إدارة المدرسة & 1 \\
\hline & & & & & & & & & & & & & & بطرق تبين أهها موقع & \\
\hline & & & & & & & & & & & & & & 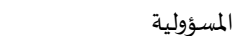 & \\
\hline \multirow[t]{2}{*}{1} & 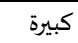 & 0.849 & 4.234 & 40.4 & 126 & 50.3 & 157 & 3.8 & 12 & 3.2 & 10 & 2.2 & 7 & للإدارة المدرسة احترامها & 2 \\
\hline & جداً & & & & & & & & & & & & & داخل المدرسة & \\
\hline \multirow[t]{4}{*}{5} & كبيرة & 0.924 & 3.910 & 24.0 & 75 & 55.4 & 173 & 9.9 & 31 & 8.7 & 27 & 1.9 & 6 & تمنح إدارة المدرسة & 3 \\
\hline & & & & & & & & & & & & & & أصحاب المسؤولية في & \\
\hline & & & & & & & & & & & & & & المدرسة صلاحيات معادلة & \\
\hline & & & & & & & & & & & & & & لحجم مسؤولياتهم & \\
\hline \multirow[t]{3}{*}{4} & كبيرة & 0.907 & 4.000 & 27.9 & 87 & 55.1 & 172 & 8.3 & 26 & 6.4 & 20 & 2.2 & 7 & تعطي إدارة الممدرسة قادهها & 4 \\
\hline & & & & & & & & & & & & & & الصلاحيات المخولة لهم & \\
\hline & & & & & & & & & & & & & & لممارسة أعمالهم & \\
\hline \multirow[t]{3}{*}{2} & كبيرة & 0.869 & 4.138 & 35.3 & 110 & 51.9 & 162 & 5.8 & 18 & 5.4 & 17 & 1.6 & 5 & تحافظ إدارة المدرسة على & 5 \\
\hline & & & & & & & & & & & & & & خط سير المدرسة & \\
\hline & كبيرة & 0.870 & 4.078 & & & & 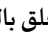 & 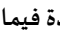 & 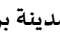 & 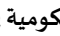 & وية & 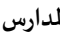 & إمية في & بط العام لمستوى القيم الت & 1 \\
\hline
\end{tabular}

يتضح من الجدول السـابق أن:

مستوى القيم التنظيمية المدارس الثانوية الحكومية في مدينة بريدة من وجهة نظر المعلمات فيما يتعلق بالقوة كبعد من المحور الرئيس الأول

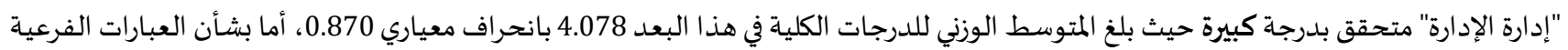

في هذا البعد فجاءت مرتبة حسب درجة التحقق كالتالي:

جاءت العبارة "لإدارة المدرسة احترامها داخل المدرسة" في الترتيب الأول من حيث درجة التحقق، ومتحققة بدرجة كبيرة جداً حيث بلغت قيمة

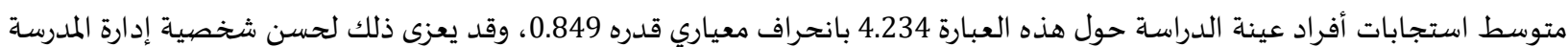


ومحافظتها على القواعد والتعليمات المخولة لها وهذا يعكس امتلاك الإدارة على امتلاك ابرز المعلومات التي تعينها على إدارة المدرسة بصورة فاعلة .

جاءت العبارة "تمنح إدارة المدرسة أصحاب المسؤولية في المدرسة صلاحيات معادلة لحجم مسؤولياتهم" في الترتيب الخامس من حيث درجة التحقق، ومتحققة بدرجة كبيرة حيث بلغت قيمة متوسط استجابات أفراد عينة الدراسة حول هذه العبارة 3.910 بانحراف معياري قدره 0.924، وقد يعزى ذلك لثقة إدارة المدرسة بالمعلمات المتميزات مما يخلق لهن نوع من الحرية ورفع روحهن المعنوية .

البعد الثاني: الصفوة:

جدول (7): التكرارات والنسب المئوية والمتوسطات والانحر افات المعيارية لاستجابات عينة الدراسة حول مستوى القيم التنظيمية في المدارس الثانوية

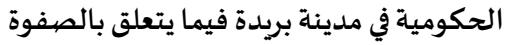

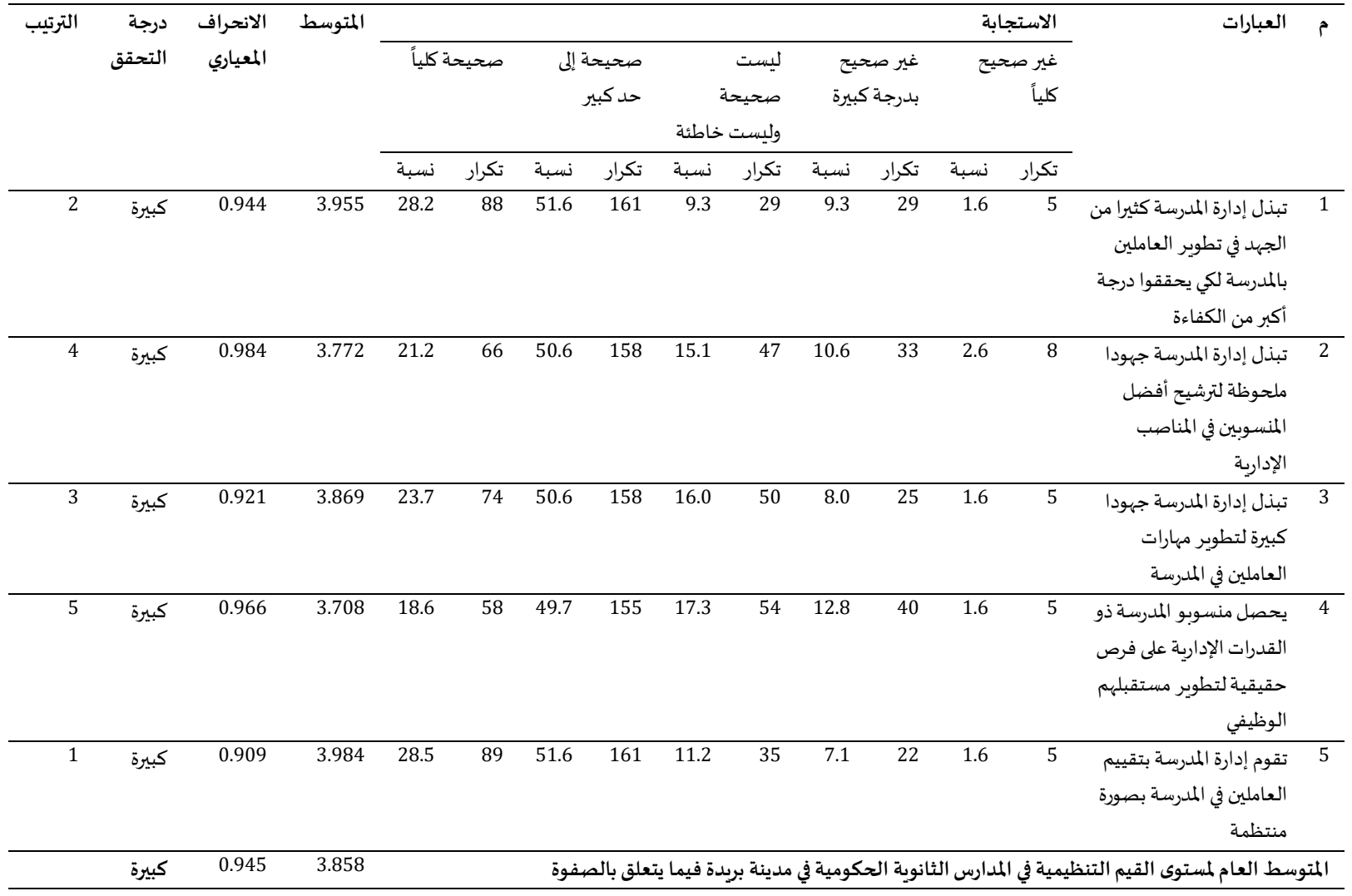

يتضح من الجدول السـابق أن:

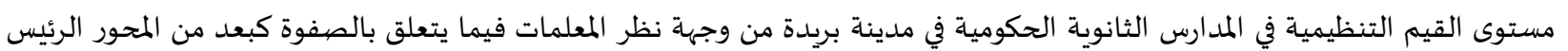
الأول "إدارة الإدارة" متحقق بدرجة كبيرة حيث بلغ المتوسط الوزني للدرجات الكلية في هذا البعد 3.858 بانحراف معياري 0.945، أما بشأن العبارات الفرعية في هذا البعد فجاءت مرتبة حسب درجة التحقق كالتالي: جاءت العبارة "تقوم إدارة المدرسة بتقييم العاملين في المدرسة بصورة منتظمة" في الترتيب الأول من حيث درجة التحقق، ومتحققة بدرجة كبيرة حيث بلغت قيمة متوسط استجابات أفراد عينة الدراسة حول هذه العبارة 3.984 بانحراف معياري قدره 0.909، وقد يعزى ذلك للاهتمام

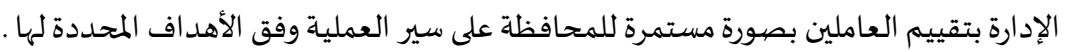
جاءت العبارة "يحصل منسوبو المدرسة ذو القدرات الإدارية على فرص حقيقية لتطوير مستقبلهم الوظيفي" في الترتيب الخامس من حيث درجة التحقق، ومتحققة بدرجة كبيرة حيث بلغت قيمة متوسط استجابات أفراد عينة الدراسة حول هذه العبارة 3.708 بانحراف معياري قدره 0.966، وقد يعزى ذلك لحرص الإدارة على إعطاء فرص للمعلمات لتطوير مستقبلهن الوظيفي وفق امكانياتهن وقدراتهن. 
البعد الثالث: المكافأة:

جدول (8): التكرارات والنسب المئوية والمتوسطات والانحر افات المعيارية لاستجابات عينة الدراسة حول مستوى القيم التنظيمية في المدارس الثانوية الحكومية في مدينة بريدة فيما يتعلق بالمكافأة

\begin{tabular}{|c|c|c|c|c|c|c|c|c|c|c|c|c|c|c|c|}
\hline \multirow[t]{5}{*}{ الترتيب } & \multirow{5}{*}{ درجة } & \multirow{5}{*}{ الالمعياري } & \multirow[t]{5}{*}{ المتوسط } & & & & & & & & & \multicolumn{2}{|c|}{ الاستجابة } & \multirow[t]{5}{*}{ العبارات } & \multirow[t]{5}{*}{ م } \\
\hline & & & & \multirow{2}{*}{\multicolumn{2}{|c|}{ صحيحة كلياً }} & \multirow{2}{*}{\multicolumn{2}{|c|}{ حد كيحة إلى }} & & ليست & \multirow{2}{*}{\multicolumn{2}{|c|}{ غير صحيح }} & \multirow{2}{*}{\multicolumn{2}{|c|}{ غلياً صحيح }} & & \\
\hline & & & & & & & & & صحيح & & & & & & \\
\hline & & & & \multicolumn{10}{|c|}{ وليست خاطئة } & & \\
\hline & & & & نسبة & 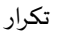 & نسبة & 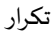 & نسبة & تكرار & نسبة & 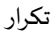 & نسبة & ت تكرار & & \\
\hline \multirow[t]{2}{*}{4} & كبيرة & 1.102 & 3.538 & 17.3 & 54 & 46.2 & 144 & 13.5 & 42 & 19.2 & 60 & 3.8 & 12 & تكافئ إدارة المدرسة الأداء & 1 \\
\hline & & & & & & & & & & & & & & المتميز للعاملين بسخاء & \\
\hline \multirow[t]{4}{*}{3} & كبيرة & 1.037 & 3.673 & 19.6 & 61 & 47.1 & 147 & 18.6 & 58 & 10.6 & 33 & 4.2 & 13 & تعطي إدارة المدرسة & 2 \\
\hline & & & & & & & & & & & & & & العاملين تغذية راجعة عن & \\
\hline & & & & & & & & & & & & & & كيفية أدائهم بصورة & \\
\hline & & & & & & & & & & & & & & منتظمة & \\
\hline \multirow[t]{3}{*}{5} & متوسطة & 1.110 & 3.378 & 11.9 & 37 & 45.2 & 141 & 18.6 & 58 & 17.6 & 55 & 6.7 & 21 & تربط إدارة المدرسة المكافأة & 3 \\
\hline & & & & & & & & & & & & & & الإدارية ـ بصورة واضحة & \\
\hline & & & & & & & & & & & & & & ل للعاملين & \\
\hline \multirow[t]{3}{*}{1} & 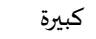 & 1.014 & 3.910 & 29.2 & 91 & 48.4 & 151 & 9.0 & 28 & 11.2 & 35 & 2.2 & 7 & تأخذ إدارة المدرسة بالأداء & 4 \\
\hline & & & & & & & & & & & & & & كمعيار أساسي لتقييم & \\
\hline & & & & & & & & & & & & & & العاملين & \\
\hline \multirow[t]{5}{*}{2} & كبيرة & 1.084 & 3.769 & 26.0 & 81 & 45.8 & 143 & 10.3 & 32 & 15.1 & 47 & 2.9 & 9 & تكافئ إدارة المدرسة & 5 \\
\hline & & & & & & & & & & & & & & العاملين على عمل الأشياء & \\
\hline & & & & & & & & & & & & & & التي تساعد على نجاح & \\
\hline & & & & & & & & & & & & & & المدرسة & \\
\hline & كبيرة & 1.069 & 3.654 & & & & 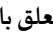 & 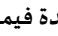 & 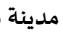 & كومية - & 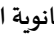 & 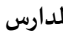 & 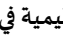 & ط العام لمستوى القيم ال & \\
\hline
\end{tabular}

يتضح من الجدول السابق أن:

مستوى القيم التنظيمية في المدارس الثانوية الحكومية في مدينة بريدة من وجهة نظر الماند المعلمات فيما يتعلق بالمكافأة كبعد من المحور الرئيس الأول "إدارة الإدارة" متحقق بدرجة كبيرة حيث بلغ المتوسط الوزني للدرجات الكلية في هذا البعد 3.654 بانحراف معياري 1.069، أما بشأن العبارات الفرعية في هذا البعد فجاءت مرتبة حسب درجة التحقق كالتالي: جاءت العبارة "تأخذ إدارة المدرسة بالأداء كمعيار أسـاسي لتقييم العاملين" في الترتيب الأول من حيث درجة التحقق، ومتحققة بدرجة كبيرة حيث

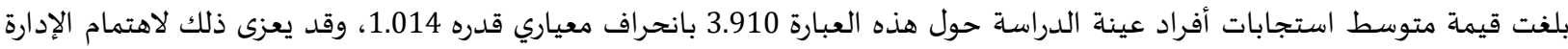

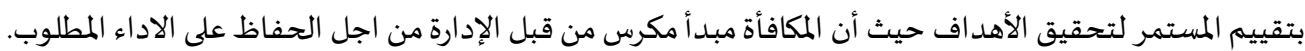
جاءت العبارة "تربط إدارة المدرسة المكافأة الإدارية ـ بصورة واضحة للعاملين" في الترتيب الخامس من حيث درجة التحقق، ومتحققة بدرجة متوسطة حيث بلغت قيمة متوسط استجابات أفراد عينة الدراسة حول هذه العبارة 3.378 بانحراف معياري قدره 1.110، وقد يعزى ذلك لعدم

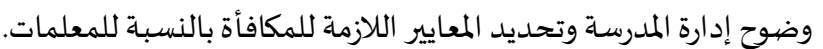
ومجمل ما تم التوصل إليه من نتائج فيما يتعلق بمستوى القيم التنظيمية لدى معلمات المدارس الثانوية الحكومية في مدينة بريدة فيما يتعلق

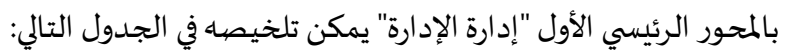

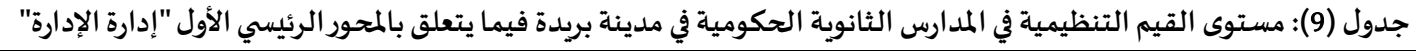

\begin{tabular}{|c|c|c|c|c|}
\hline 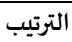 & درجة التحقق & الانحراف المعياري & المتوسط الوزني & المحور الرئيس الأول: إدارة الإدارة \\
\hline 1 & كبيرة & 0.870 & 4.078 & 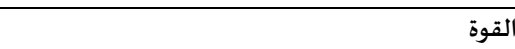 \\
\hline 2 & كبيرة & 0.945 & 3.858 & 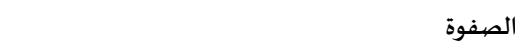 \\
\hline 3 & كبيرة & 1.069 & 3.654 & المكافأة \\
\hline \multicolumn{2}{|c|}{ كبيرة } & 0.961 & 3.863 & الدرجة الكلية لمستوى المحور الرئيس الأول: "إدارة الإدارة" \\
\hline
\end{tabular}

يتضح من الجدول السابق أن مستوى القيم التنظيمية في المدارس الثانوية لدى معلمات الحكومية في مدينة بريدة فيما يتعلق بالمحور الرئيسي الأول "إدارة الإدارة" جاء متحققاً بدرجة كبيرة بمتوسط وزني 3.863 وانحراف معياري 0.961، وجاء في الترتيب الأول بعد القوة ومتحقق بدرجة كبيرة

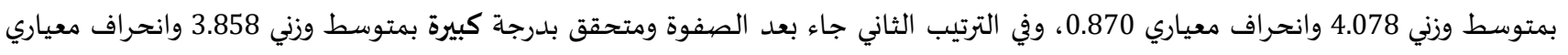


0.945 وفي الترتيب الثالث والأخير جاء بعد المكافأة ومتحقق بدرجة كبيرة بمتوسط وزني 3.654 وانحراف معياري 1.069، يعزى ذلك لامتلاك الإدارة

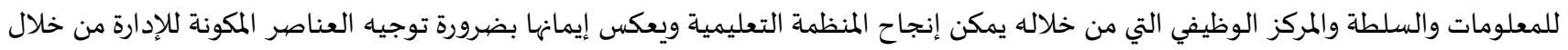

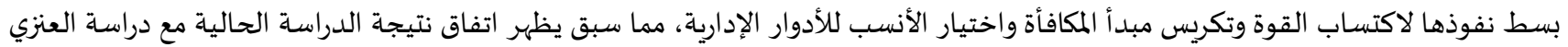

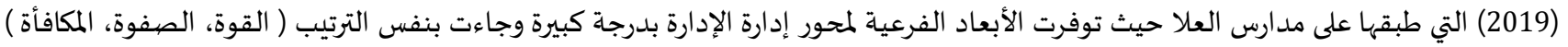

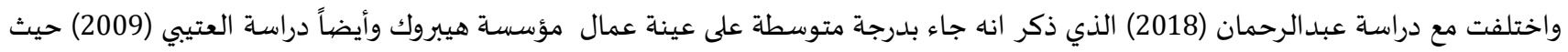
جاء محور إدارة الإدارة بدرجة متوسطة أيضاً في مؤسسات التعليم والتدريب العالي التقني والمنين في المدينة المنورة. 2. النسبة للمحور الرئيس الثاني: إدارة العلاقات:

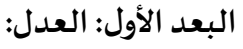

جدول (10): التكرارات والنسب المئوية والمتوسطات والانحر افات المعيارية لاستجابات عينة الدراسة حول مستوى القيم التنظيمية في المدارس الثانوية

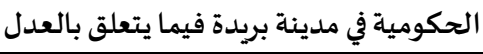

\begin{tabular}{|c|c|c|c|c|c|c|c|c|c|c|c|c|c|c|c|}
\hline \multirow[t]{5}{*}{ الترتيب } & \multirow{5}{*}{ درجة } & \multirow{5}{*}{ المعياري الانحراف } & \multirow[t]{5}{*}{ المتوسط } & & & & & & & & & \multicolumn{2}{|c|}{ الاستجابة } & \multirow[t]{5}{*}{ العبارات } & \multirow[t]{5}{*}{ 5 } \\
\hline & & & & \multirow{2}{*}{\multicolumn{2}{|c|}{ صحيحة كلياً }} & \multirow{2}{*}{\multicolumn{2}{|c|}{ حد كيحة إلى }} & & 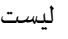 & \multirow{2}{*}{\multicolumn{2}{|c|}{ غير صحيح }} & \multirow{2}{*}{\multicolumn{2}{|c|}{ غلياً صحيح }} & & \\
\hline & & & & & & & & & صحيح & & & & & & \\
\hline & & & & \multicolumn{10}{|c|}{ وليست خاطئة } & & \\
\hline & & & & نسبة & تكرار & نسبة & 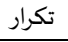 & نسبة & تكرار & نسبة & 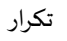 & نسبة & 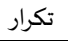 & & \\
\hline \multirow[t]{3}{*}{1} & كبيرة & 0.981 & 4.122 & 40.7 & 127 & 42.6 & 133 & 7.1 & 22 & 7.4 & 23 & 2.2 & 7 & تتعاطف إدارة المدرسة مع & 1 \\
\hline & & & & & & & & & & & & & & العاملين الذين يواجهون & \\
\hline & & & & & & & & & & & & & & صعوبات حقيقية & \\
\hline \multirow[t]{4}{*}{3} & كبيرة & 0.979 & 4.006 & 33.7 & 105 & 46.2 & 144 & 9.0 & 28 & 9.6 & 30 & 1.6 & 5 & تمنح إدارة المدرسة & 2 \\
\hline & & & & & & & & & & & & & & العاملين فرصة عادلة & \\
\hline & & & & & & & & & & & & & & لسماع شكواهم عندما & \\
\hline & & & & & & & & & & & & & & تنشأ خلافات ما & \\
\hline \multirow[t]{4}{*}{4} & كبيرة & 0.895 & 3.984 & 28.2 & 88 & 51.6 & 161 & 11.9 & 37 & 7.1 & 22 & 1.3 & 4 & يعكس سلوك إدارة & 3 \\
\hline & & & & & & & & & & & & & & المدرسة مدى اهتمامهيم & \\
\hline & & & & & & & & & & & & & & بمصلحة العاملين في & \\
\hline & & & & & & & & & & & & & & المدرسة & \\
\hline \multirow[t]{2}{*}{2} & كبيرة & 0.943 & 4.029 & 32.1 & 100 & 50.3 & 157 & 8.3 & 26 & 7.1 & 22 & 2.2 & 7 & تعتبر المدرسـة مكانا جيدا & 4 \\
\hline & & & & & & & & & & & & & & ل ل ل لعمل & \\
\hline \multirow[t]{3}{*}{5} & متوسطة & 1.229 & 2.840 & 8.3 & 26 & 28.8 & 90 & 16.0 & 50 & 32.1 & 100 & 14.7 & 46 & توجد في المدرسة طبقية & 5 \\
\hline & & & & & & & & & & & & & & هدامة أو عوائق عنصرية & \\
\hline & كبيرة & 1.005 & 3.796 & & & 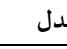 & 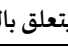 & 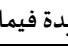 & 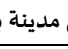 & كومية & مثانوية & 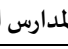 & 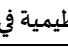 & سط العام لمستوى القيم الـ & \\
\hline
\end{tabular}

يتضح من الجدول السابق أن:

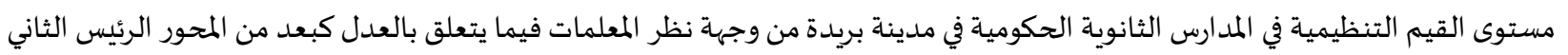

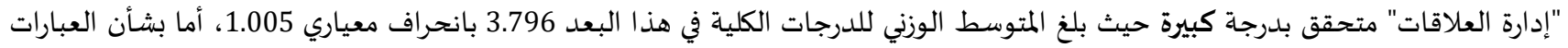

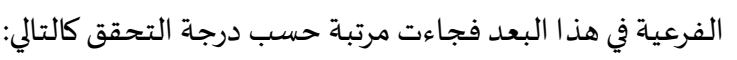
• جاءت العبارة "تتعاطف إدارة المدرسة مع العاملين الذين يواجهون صعوبات حقيقية" في الترتيب الأول من حيث درجة التحقق، ومتحققة بدرجة فئة كبيرة حيث بلغت قيمة متوسط استجابات أفراد عينة الدراسة حول هذه العبارة 4.122 بانحراف معياري قدره إدارة المدرسة بظروف العاملين وتراعي ظروفهم والصعوبات التي تواجههم وتكون معينه لهم الهئ.

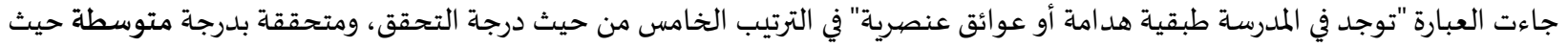

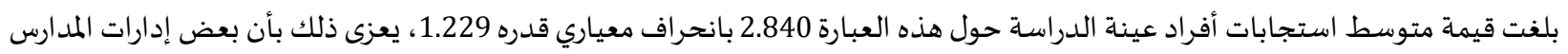
تدرك أن العلاقة بينها وبين العاملين قائمة على أن تكون دقيقة ومثمرة بعيدة عن العنصرية . 
البعد الثاني: فرق العمل:

جدول (11): التكرارات والنسب المئوية والمتوسطات والانحر افات المعيارية لاستجابات عينة الدراسة حول مستوى القيم التنظيمية في المدارس الثانوية الحكومية في مدينة بريدة فيما يتعلق بفرق العمل

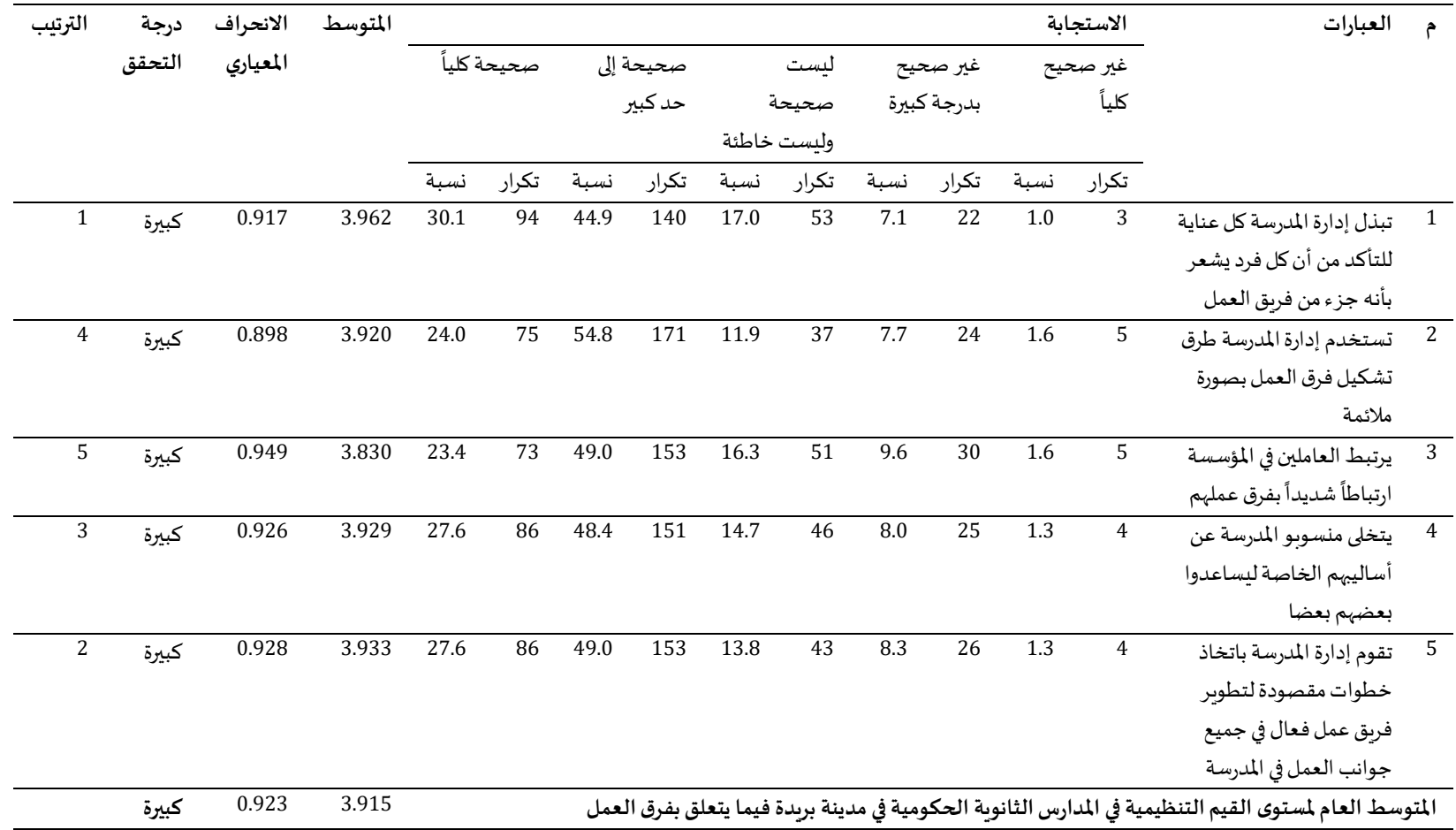

يتضح من الجدول السابق أن:

مستوى القيم التنظيمية المدارس الثانوية الحكومية في مدينة بريدة من وجهة نظر المعلمات فيما يتعلق بفرق العمل كبعد من المحور الرئيس الثاني "إدارة العلاقات" متحقق بدرجة كبيرة حيث بلغ المتوسط الوزني للدرجات الكلية في هذا البعد الفرعية في هذا البعد فجاءت مرتبة حسب درجة التحقق كالتالي:

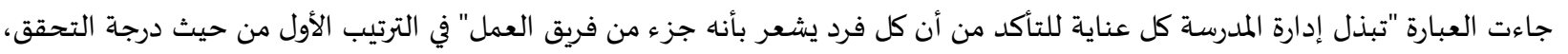
ومتحققة بدرجة كبيرة حيث بلغت قيمة متوسط استجابات أفراد عينة الدراسة حول هذه العبارة 3.962 بانحراف معياري قدره 0.917، قد يعزى ذلك لوجود إدارة فعالة تهتم تحرص على العمل بروج الفريق وحريصة بأن يسودها بلتها الثقة المتبادلة

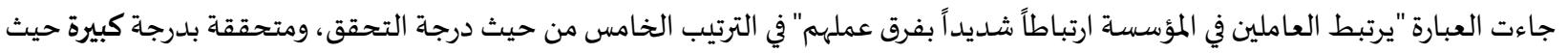

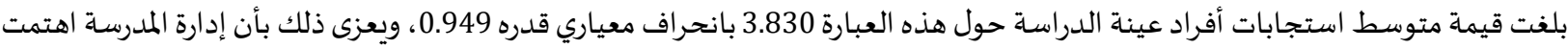

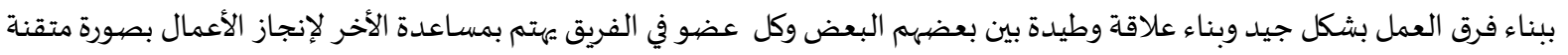
البعد الثالث: القانون والنظام:

جدول (12): التكرارات والنسب المئوية والمتوسطات والانحر افات المعيارية لاستجابات عينة الدراسة حول مستوى القيم التنظيمية في المدارس الثانوية

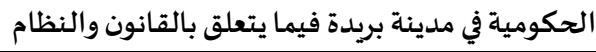

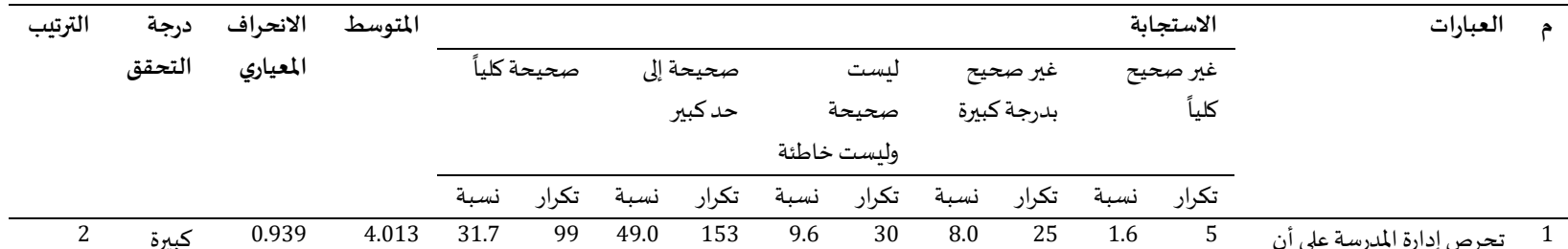

تكون القواعد والإجراءات

التنظيمية في المدرسة عادلة

\begin{tabular}{|c|c|c|c|c|c|c|c|c|c|c|c|c|c|c|c|}
\hline 4 & كبيرة & 1.011 & 3.901 & 29.2 & 91 & 46.5 & 145 & 12.2 & 38 & 9.6 & 30 & 2.6 & 8 & تطبق إدارة المدرسة العدل في & 2 \\
\hline 1 & كبيرة & 0.941 & 4.038 & 33.7 & 105 & 47.1 & 147 & 10.6 & 33 & 6.7 & 21 & 1.9 & 6 & تفهم إدارة المدرسة المبادئ & 3 \\
\hline
\end{tabular}




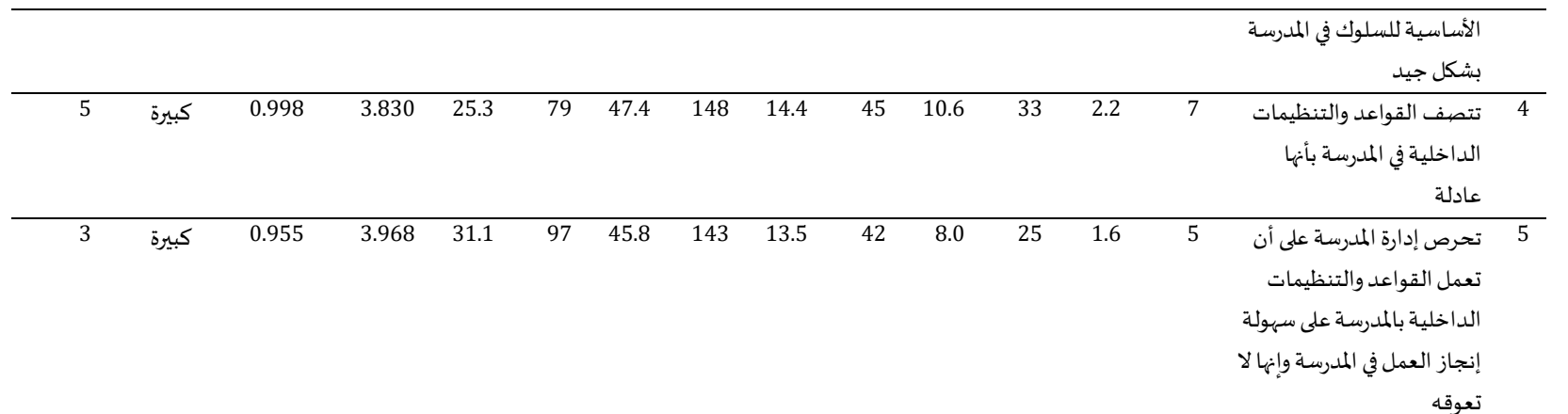

مستوى القيم التنظيمية في المدارس الثانوية الحكومية في مدينة بريدة من وجهة نظر المعلمات فيما يتعلق بالقانون والنظام كبعد من المبان المحتور

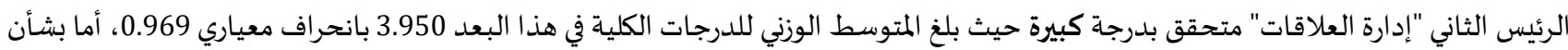

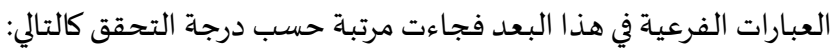

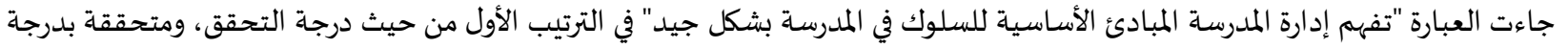

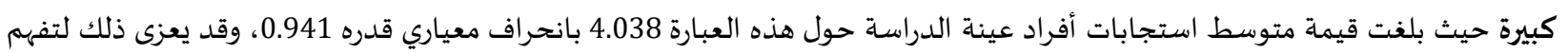

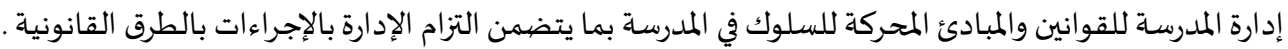

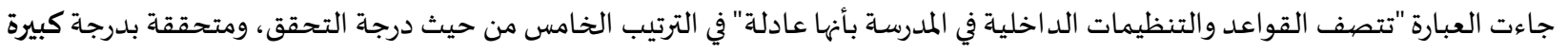

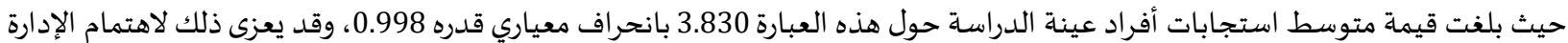

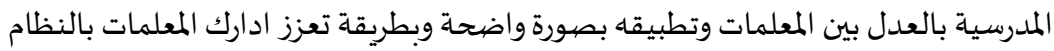

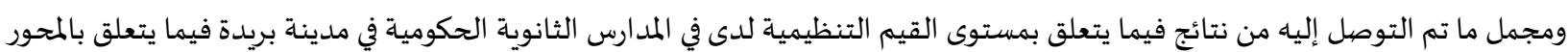
الرئيسي الثاني "إدارة العلاقات" يمكن تلخيصها في الجدول التالي:

\begin{tabular}{|c|c|c|c|c|}
\hline الترتيب & درجة التحقق & الانحراف المعياري & المتوسط الوزني & المحور الرئيس الثاني: إدارة العلاقات \\
\hline 3 & كبيرة & 1.005 & 3.796 & العدل \\
\hline 2 & كبيرة & 0.923 & 3.915 & 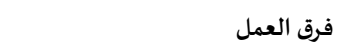 \\
\hline 1 & 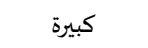 & 0.969 & 3.950 & القانون والنظام \\
\hline & & 0.966 & 3.887 & الدرجة الكلية لمستوى المحور الرئيس | \\
\hline
\end{tabular}

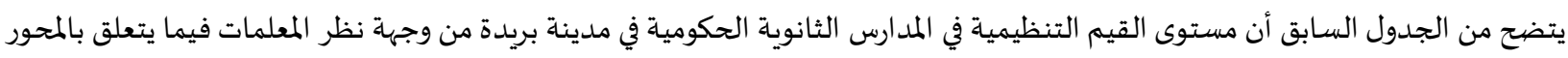

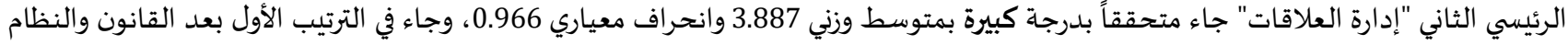

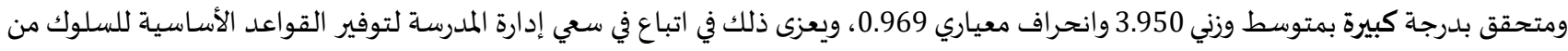

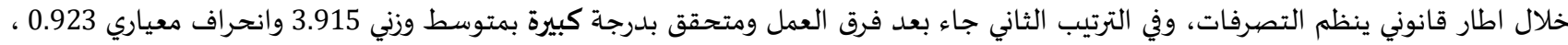

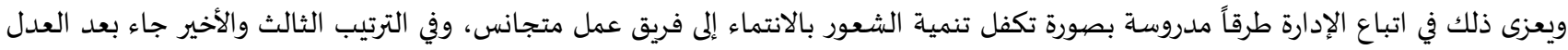

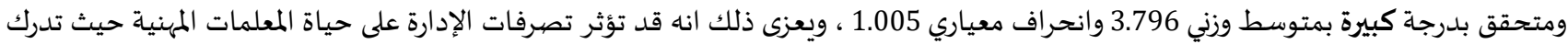

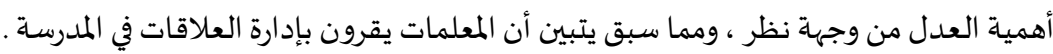

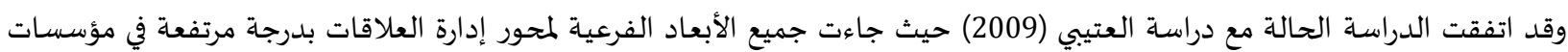

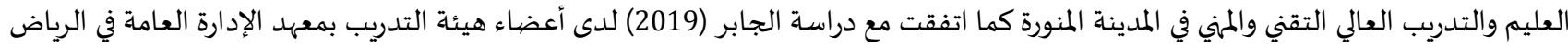

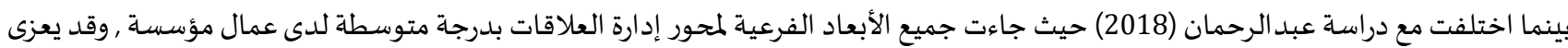
ذلك الاختلاف البيئة المطبقة فهيا الدراسة.

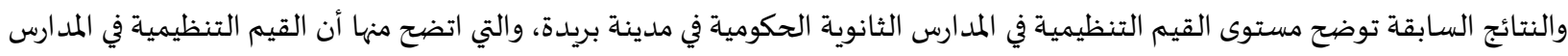
الثانوية الحكومية في مدينة بريدة من وجهة نظر المعلمات مستواها كبير، ويمكن تلخيص النتائج السابقة في الجدول التالي: 
جدول (14): مستوى القيم التنظيمية في المدارس الثانوية الحكومية في مدينة بريدة

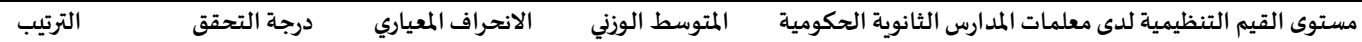

في مدينة بريدة

\begin{tabular}{|c|c|c|c|c|}
\hline 2 & كبيرة & 0.961 & 3.863 & مستوى المحور الرئيس الأول: "إدارة الإدارة" \\
\hline \multirow[t]{2}{*}{1} & كبيرة & 0.966 & 3.887 & مستوى المحور الرئيس الثاني: "إدارة العلاقات" \\
\hline & كبيرة & 0.964 & 3.875 & مستدة من القيم التنظيمية في المدارس الثانوية الحكومية في مدينة \\
\hline
\end{tabular}

يتضح من الجدول السابق أن مستوى القيم التنظيمياة لدى معلمات المهردات المدارس الثانوية الحكومياة في مدينة بريدة وجهة نظر المعلمات جاء متحققاً

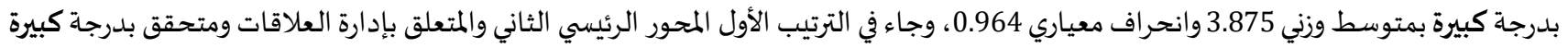

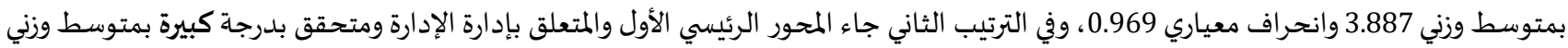
0.961 وانحراف معياري 3.863

ثانياً: نتائج إجابة السؤال الثاني: ينص السؤال الثاني للبحث الحالي على "هل توجد فروق ذات دلالة إحصائية في مستوى القيم التنظيمية للمعلمات في المدارس الثانوية الحكومية في مدينة بريدة تعزى لمتغيرات (سنوات الخبرة، التخصص، الدورات التدريبية)؟" 1. بالنسبة لمتغيرسنوات الخبرة:

تم استخدام اختبار تحليل التباين أحادي الاتجاه One Way ANOVA في الكشف عن دلالة الفروق في مستوى القيم التنظيمية للمعلمات في المدارس الثانوية الحكومية في مدينة بريدة والتي ترجع لاختلاف سنوات الخبرة (أقل من 5 سنوات، من 5 سنوات إلى أقل من 10 سنوات، من 10 سنوات فأكثر) فكانت النتائج كما هي موضحة في التالي:

جدول (15): المتوسطات والانحر افات المعيارية لمستوى القيم التنظيمية للمعلمات في المدارس الثانوية الحكومية في مدينة بريدة وفقاً لسنوات الخبرة

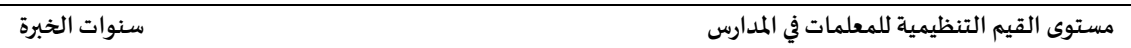

الثانوية الحكومية في مدينة بريدة

\begin{tabular}{|c|c|c|c|c|c|c|c|}
\hline انحراف معياري & متوسط & انحراف معياري & متوسط & انحراف معياري & متوسط & & \\
\hline 3.586 & 20.473 & 2.399 & 20.571 & 4.437 & 19.933 & القوة & المححور الرئيس الأول: \\
\hline 3.939 & 19.302 & 3.320 & 19.614 & 4.466 & 18.867 & الصفوة & "إدارة الإدارة" \\
\hline 4.454 & 17.852 & 4.221 & 18.500 & 4.395 & 19.267 & المكافأة & \\
\hline 10.685 & 57.626 & 8.672 & 58.686 & 12.334 & 58.067 & درجة كلية & \\
\hline 3.176 & 19.066 & 2.413 & 18.943 & 3.466 & 18.767 & العدل & المحور الرئيس الثاني: \\
\hline 3.806 & 19.582 & 3.194 & 19.729 & 4.636 & 19.367 & فرق العمل & "إدارة العلاقات" " \\
\hline 4.256 & 19.670 & 3.755 & 19.700 & 4.810 & 20.050 & القانون والنظام & \\
\hline 10.236 & 58.319 & 7.559 & 58.371 & 11.664 & 58.183 & درجة كلية & \\
\hline 19.915 & 115.945 & 15.445 & 117.057 & 22.802 & 116.250 & & الدرجة الكلية للقيم ال: \\
\hline
\end{tabular}

جدول (16): دلالة الفروق في استجابات أفراد عينة الدراسة حول مستوى القيم التنظيمية للمعلمات في المدارس الثانوية الحكومية في مدينة بريدة باختلاف

\begin{tabular}{|c|c|c|c|c|c|c|c|}
\hline \multicolumn{8}{|c|}{ سنوات الخبرة } \\
\hline \multirow{3}{*}{ مستوى الدلالة } & \multirow{3}{*}{ قيمة "ف" } & \multirow{3}{*}{$\begin{array}{r}\text { متوسط المربعات } 8.028 \\
\end{array}$} & \multirow{3}{*}{ درجات الحرية } & \multirow{3}{*}{$\begin{array}{r}\text { مجموع المربعات } \\
16.056\end{array}$} & \multirow{3}{*}{ مصيدر التباين } & \multirow{2}{*}{\multicolumn{2}{|c|}{ مستوى القيم التنظيمية للمعلمات في المدارس }} \\
\hline & & & & & & & \\
\hline & & & & & & \multirow[t]{3}{*}{ القوة } & المحور الرئيس الأول: \\
\hline & & 12.577 & 309 & 3886.239 & داخل المجموعات & & "إدارة الإدارة" \\
\hline & & & 311 & 3902.295 & الكلي & & \\
\hline \multirow{3}{*}{ 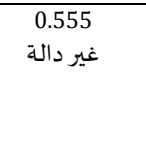 } & 0.591 & 9.070 & 2 & 18.140 & بين المجموعات & \multirow[t]{3}{*}{ الصفوة } & \\
\hline & & 15.359 & 309 & 4745.898 & داخل المجموعات & & \\
\hline & & & 311 & 4764.038 & الكلي & & \\
\hline \multirow{3}{*}{ 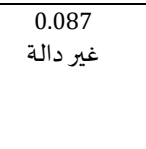 } & 2.467 & 47.578 & 2 & 95.157 & بين المجموعات & \multirow[t]{3}{*}{ المكافأة } & \\
\hline & & 19.289 & 309 & 5960.228 & داخل المجموعات & & \\
\hline & & & 311 & 6055.385 & الكلي & & \\
\hline \multirow{2}{*}{$\begin{array}{c}0.774 \\
\text { غير دالة }\end{array}$} & 0.256 & 28.884 & 2 & 57.767 & بين المجموعات & \multirow[t]{2}{*}{ درجة كلية } & \\
\hline & & 112.717 & 309 & 34829.412 & داخل المجموعات & & \\
\hline
\end{tabular}




\begin{tabular}{|c|c|c|c|c|c|c|c|}
\hline & & & 311 & 34887.179 & الكلي & & \\
\hline \multirow{3}{*}{$\begin{array}{r}0.803 \\
\text { غير دالة }\end{array}$} & 0.220 & 2.086 & 2 & 4.171 & بين المجموعات & \multirow[t]{3}{*}{ العدل } & المحور الرئيس الثاني: \\
\hline & & 9.501 & 309 & 2935.714 & داخل المجموعات & & "إدارة العلاقات" \\
\hline & & & 311 & 2939.885 & الكلي & & \\
\hline \multirow{3}{*}{$\begin{array}{r}0.866 \\
\text { غير دالة }\end{array}$} & 0.143 & 2.132 & 2 & 4.265 & بين المجموعات & \multirow[t]{3}{*}{ فرق العمل } & \\
\hline & & 14.867 & 309 & 4594.040 & داخل المجموعات & & \\
\hline & & & 311 & 4598.304 & الكلي & & \\
\hline \multirow{3}{*}{ غير دالة 0.831} & 0.185 & 3.365 & 2 & 6.730 & بين المجموعات & \multirow[t]{3}{*}{ القانون والنظام } & \\
\hline & & 18.174 & 309 & 5615.770 & داخل المجموعات & & \\
\hline & & & 311 & 5622.500 & ال الكلي & & \\
\hline \multirow{3}{*}{$\begin{array}{r}0.994 \\
\text { غير دالة }\end{array}$} & 0.006 & 0.616 & 2 & 1.231 & بين المجموعات & \multirow[t]{3}{*}{ درجة كلية } & \\
\hline & & 100.113 & 309 & 30934.843 & داخل المجموعات & & \\
\hline & & & 311 & 30936.074 & ال الكلي & & \\
\hline \multirow{3}{*}{$\begin{array}{r}0.922 \\
\text { غير دالة }\end{array}$} & 0.081 & 31.262 & 2 & 62.525 & بين المجموعات & \multirow{3}{*}{\multicolumn{2}{|c|}{ الدرجة الكلية للقيم التنظيمية }} \\
\hline & & 384.875 & 309 & 118926.472 & داخل المجموعات & & \\
\hline & & & 311 & 118988.997 & الكلي & & \\
\hline
\end{tabular}

يتضح من الجدول السابق أنه:

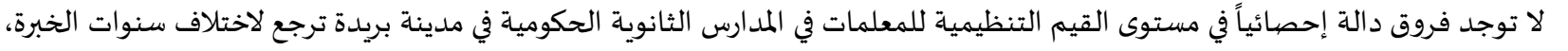
أي أن أفراد العينة من المعلمات بإخلاف سنوات خبراتهن اتفقن على ممارسة المدارس لأبعاد التهاد القيم التنظيمية.

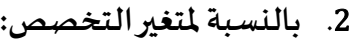

تم استخدام اختبار "ت" للمجموعات المستقلة Independent Samples T-Test في الكشف عن دلالة الفروق في مستوى القيم التنظيمية للمعلمات في المدارس الثانوية الحكومية في مدينة بريدة والتي ترجع لاختلاف التخصص (أدبي، علمي) فكانت النتائج كما هي موضحة في التالي: جدول (17): دلالة الفروق في استجابات أفراد عينة الدراسة حول مستوى القيم التنظيمية للمعلمات في المدارس الثانوبة الحكومية في مدينة بريدة باختلاف

\begin{tabular}{|c|c|c|c|c|c|c|}
\hline \multirow{3}{*}{ مستوى الدلالة } & \multirow{3}{*}{ 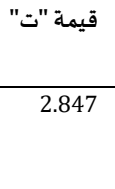 } & \multirow{2}{*}{ الانحراف المعياري } & \multirow{2}{*}{$\begin{array}{r}\text { المتوسط الحسابي } \\
20.822\end{array}$} & \multirow{2}{*}{ الدخصص أدبي } & \multicolumn{2}{|c|}{ مستوى القيم التنظيمية للمعلمات في المدارس } \\
\hline & & & & & القوة & المحور الرئيس الأول: \\
\hline & & 3.828 & 19.652 & علمي & & " إدارة الإدارة" \\
\hline \multirow[t]{2}{*}{0.01} & 2.918 & 3.601 & 19.777 & أدبي & الصفوة & \\
\hline & & 4.286 & 18.452 & علمي & & \\
\hline \multirow[t]{2}{*}{0.01} & 3.802 & 4.258 & 18.980 & أدبي & المكافأة & \\
\hline & & 4.425 & 17.052 & علمي & & \\
\hline \multirow[t]{2}{*}{0.01} & 3.627 & 9.934 & 59.579 & أدبي & درجة كلية & \\
\hline & & 11.131 & 55.157 & علمي & & \\
\hline \multirow[t]{2}{*}{0.01} & 3.650 & 2.861 & 19.457 & أدبي & العدل & المحور الرئيس الثاني: \\
\hline & & 3.263 & 18.165 & علمي & & "إدارة العلاقات" \\
\hline \multirow[t]{2}{*}{0.01} & 4.032 & 3.340 & 20.228 & أدبي & فرق العمل & \\
\hline & & 4.375 & 18.452 & علمي & & \\
\hline \multirow[t]{2}{*}{0.01} & 5.240 & 3.916 & 20.675 & أدبي & القانون والنظام & \\
\hline & & 4.353 & 18.165 & علمي & & \\
\hline \multirow[t]{2}{*}{0.01} & 4.942 & 8.747 & 60.360 & أدبي & درجة كلية & \\
\hline & & 10.954 & 54.783 & علمي & & \\
\hline \multirow[t]{2}{*}{0.01} & 4.489 & 17.657 & 119.939 & أدبي & & الدرجة الكلية للقيم الذ \\
\hline & & 21.072 & 109.939 & علمي & & \\
\hline
\end{tabular}


يتضح من الجدول السـابق أنه:

توجد فروق دالة إحصائياً عند مستوى ثقة 0.01 في مستوى القيم التنظيمية للمعلمات في المدارس الثانوية الحكومية في مدينة بريدة ترجع لاختلاف التخصص، والفروق لصالح التخصصات الأدبية، وقد يعزى ارتباط مستوى القيم التنظيمية بنوع التخصص إكثرئ من الجانب

تم استخدام اختبار تحليل التباين أحادي الاتجاه One Way ANOVA في الكشف عن دلالة الفروق في مستوى القيم التنظيمية للمعلمات في

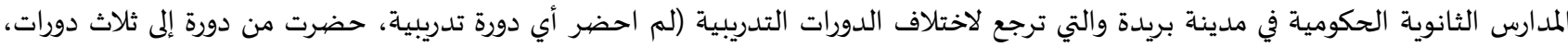

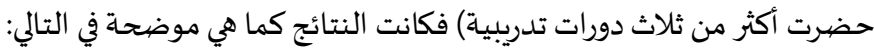

جدول (18): المتوسطات والانحر افات المعيارية لمستوى القيم التنظيمية للمعلمات في المدارس الثانوية الحكومية في مدينة بريدة وفقاً الدورات التدريبية

\begin{tabular}{|c|c|c|c|c|c|c|c|}
\hline & & & & & 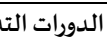 & \multirow{2}{*}{\multicolumn{2}{|c|}{ 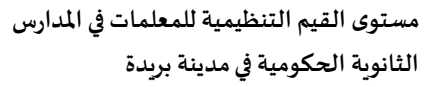 }} \\
\hline \multicolumn{2}{|c|}{ حضرت أكثر من ثلاث دورات } & \multicolumn{2}{|c|}{ حضرت من دورة إلى ثلاث دورات } & \multicolumn{2}{|c|}{ لم احضر أي دورة } & & \\
\hline انحراف معياري & متوسط & انحراف معياري & متوسط & انحراف معياري & متوسط & & \\
\hline 3.823 & 20.654 & 2.230 & 20.067 & 4.441 & 19.927 & القوة & المحور الرئيس الأول: \\
\hline 4.288 & 19.170 & 2.611 & 19.438 & 4.556 & 19.488 & الصفوة & "إدارة الإدارة" \\
\hline 4.920 & 17.885 & 3.207 & 18.685 & 4.186 & 19.073 & المكافأة & \\
\hline 11.768 & 57.709 & 6.659 & 58.191 & 12.135 & 58.488 & درجة كلية & \\
\hline 3.303 & 19.060 & 2.491 & 18.517 & 3.088 & 19.634 & العدل & المحور الرئيس الثاني: \\
\hline 4.088 & 19.698 & 3.104 & 19.461 & 4.237 & 19.268 & فرق العمل & " إدارة العلاقات" \\
\hline 4.638 & 19.604 & 3.247 & 19.809 & 4.433 & 20.268 & القانون والنظام & \\
\hline 10.956 & 58.363 & 7.423 & 57.787 & 10.373 & 59.171 & درجة كلية & \\
\hline 21.787 & 116.071 & 13.116 & 115.978 & 21.119 & 117.659 & & الدرجة الكلية للقيم الذ \\
\hline
\end{tabular}

جدول (19): دلالة الفروق في استجابات أفراد عينة الدراسة حول مستوى القيم التنظيمية للمعلمات في المدارس الثانوية الحكومية في مدينة بريدة باختلاف

\begin{tabular}{|c|c|c|c|c|c|c|c|}
\hline \multirow{2}{*}{ مستوى الدلالة } & \multirow{2}{*}{ قيمة "ف" 1.226} & \multirow{2}{*}{ متوسط المربعات 15.363} & \multirow{2}{*}{ درجات الحرية } & \multirow{2}{*}{$\begin{array}{r}\text { مجموع المربعات } 30.727 \\
\end{array}$} & \multirow{2}{*}{ مصيدر التباين } & \multicolumn{2}{|c|}{ مستوى القيم التنظيمية للمعلمات في المدارس } \\
\hline & & & & & & القوة & المحور الرئيس الأول: \\
\hline \multirow[t]{2}{*}{ غير دالة } & & 12.529 & 309 & 3871.568 & داخل المجموعات & & "إدارة الإدارة" \\
\hline & & & 311 & 3902.295 & الكلي & & \\
\hline \multirow{3}{*}{ 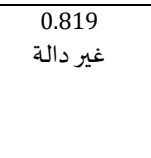 } & 0.200 & 3.082 & 2 & 6.165 & بين المجموعات & الصفوة & \\
\hline & & 15.398 & 309 & 4757.874 & داخل المجموعات & & \\
\hline & & & 311 & 4764.038 & الكلي & & \\
\hline \multirow{3}{*}{ 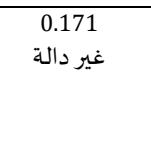 } & 1.777 & 34.418 & 2 & 68.836 & بين المجموعات & المكافأة & \\
\hline & & 19.374 & 309 & 5986.548 & داخل المجموعات & & \\
\hline & & & 311 & 6055.385 & الكلي & & \\
\hline \multirow{3}{*}{ غير دالة } & 0.122 & 13.808 & 2 & 27.617 & بين المجموعات & درجة كلية & \\
\hline & & 112.814 & 309 & 34859.563 & داخل المجموعات & & \\
\hline & & & 311 & 34887.179 & ال الكلي & & \\
\hline \multirow{3}{*}{ 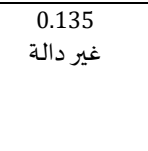 } & 2.013 & 18.906 & 2 & 37.813 & بين المجموعات & العدل & المحور الرئيس الثاني: \\
\hline & & 9.392 & 309 & 2902.072 & داخل المجموعات & & "إدارة العلاقات" \\
\hline & & & 311 & 2939.885 & ال الكلي & & \\
\hline \multirow{3}{*}{$\begin{array}{c}0.770 \\
\text { غير دالة }\end{array}$} & 0.261 & 3.882 & 2 & 7.764 & بين المجموعات & فرق العمل & \\
\hline & & 14.856 & 309 & 4590.540 & داخل المجموعات & & \\
\hline & & & 311 & 4598.304 & الكلي & & \\
\hline \multirow{2}{*}{ غير دالة } & 0.418 & 7.591 & 2 & 15.182 & بين المجموعات & القانون والنظام & \\
\hline & & 18.147 & 309 & 5607.318 & داخل المجموعات & & \\
\hline
\end{tabular}




\begin{tabular}{|c|c|c|c|c|c|c|}
\hline & & & 311 & 5622.500 & الكلي & \\
\hline \multirow{3}{*}{$\begin{array}{c}0.759 \\
\text { غير دالة }\end{array}$} & 0.276 & 27.630 & 2 & 55.259 & بين المجموعات & \multirow[t]{3}{*}{ درجة كلية } \\
\hline & & 99.938 & 309 & 30880.815 & داخل المجموعات & \\
\hline & & & 311 & 30936.074 & ال الكلي & \\
\hline \multirow{3}{*}{$\begin{array}{c}0.885 \\
\text { غير دالة }\end{array}$} & 0.122 & 46.875 & 2 & 93.751 & بين المجموعات & \multirow[t]{3}{*}{ الدرجة الكلية للقيم التنظيمية } \\
\hline & & 384.774 & 309 & 118895.246 & داخل المجموعات & \\
\hline & & & 311 & 118988.997 & الكلي & \\
\hline
\end{tabular}

يتضح من الجدول السابق أنه: • لا توجد فروق دالة إحصائياً في مستوى القيم التنظيمية للمعلمات في المدارس الثانوية الحكومية في مدينة بريدة ترجع لاختلاف الدورات التدريبية.

نتائج إجابة السؤال الثالث: ينص السؤال الثالث للدراسة " ما المقترحات اللازمة لتحسين مستوى القيم التنظيمية في المدارس الثانوية الحكومية

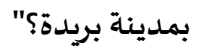

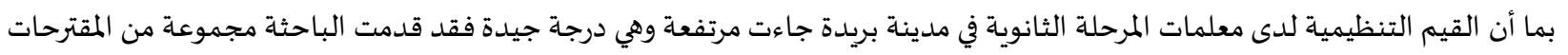
و التي من خلالها يمكن المحافظة على هذا المستوى في القيم التنظيمية: • المحافظة على الدعم الكامل للمعلمات في المؤسسات التعليمية، وتهيئة الظروف التنظيمية المناسبة لهم. بناء دورات تدريبية مناسبة لتطوير مهارات للعاملين في المؤسسات التعليمية وخاصة تلك التي تعنى بالقيم التنظيمية. إعداد برامج تدريبية مواكبة للدور القيادي المأمول، لترسيخ القيم التنظيمية. الاهتمام بكل ما من شأنه تعزيز وتنمية القيم التنظيمية داخل تلك المؤسسات من خلال تقديم المكافأة وحوافز تسههم في توفير بيئة العمل

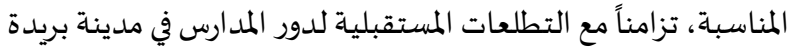
توفير نظم معلومات، وتحديد خطوط ومستويات مناسبة للسلطة تساعد المؤسسة التعليمية والتدريبية على القيام بالأدوار المناطة بها. التوصيات: بالنظر إلى واقع النظام الإداري في المملكة العربية السعودية ذو الطابع الإسلامي العربي، توصي الدراسة بالاستفادة من معطيات تلك

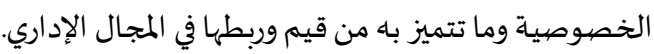
أن يعمل القائد على نشر ورعاية القيم الإيجابية في المنظمة. العمل على توظيف القيم التنظيمية بكل أبعادها في الأداء كونها تعتبر الضابط والموجهة للأداء. تعزيز طرق التواصل الإيجابي وتحفيز العاملين.

الدراسات المقترحة:

دراسة متغير القيم التنظيمية في المدراس الأهلية. إجراء المزيد من الدراسات المتعلقة بالقيم التنظيمية وعلاقتها بأنماط قيادية أخرى. توسيع نطاق الدراسة ليشمل دراسة قيم تنظيمية أخرى. استخدام أساليب جمع معلومات متعددة مثل اسلوب تحليل المحتوى والمقابلة.

1. البعداني، عبدالملك محمد ملهي (2017). دور أخلاقيات العمل والقيم التنظيمية في الرضا والأداء الوظيفي للعاملين: دراسة تطبيقية في

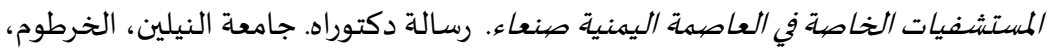
2. بن حامد، عادل (2017). القيم التنظيمية وانعكاسها على جودة التعليم العالي: دراسة مسحية للأساتذة الباحثين في علم الاجتماع بجامعادة

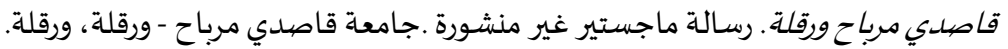
3. بودهري وعبد الرحمن (2018). القيم التنظيمية وعلاقتها بمستوى الالتزام التنظيمي دراسة ميدانية على عينة من عمال مؤسسة" هيبروك. 
4. بوقـراف، المسعود، دومة، عبد القادر (2017). القيـم التنظيمية وعلاقتها بالالتزام التنظيـم.

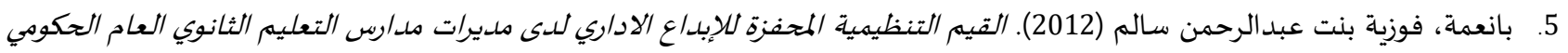

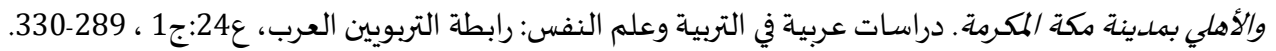
6. جامعة مؤتا، الأردن . 7. التلباني، نهاية، فارس، محمد جودت، والوحيدي، رافع يوسف (2015). القيم التنظيمية وعلاقتها بالانغماس الوظيفي: دراسة ميد/نية على

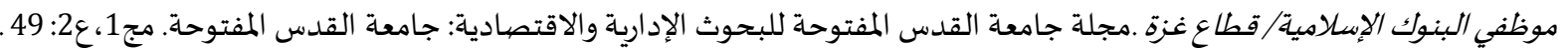
8. الجابر ، لطيفة بنت إبراهيم بن محمد (2019). القيم التنظيمية وعلاقتها بالتسرب الوظيفي من وجهة نظر أعضاء هيئة التدربي بمعهد الإدارة

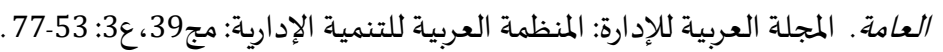
9 9. الجلاد ، ماجد زكي (2005).تعلم القيمروتعليمها. ط2 ، ، دار المسيرة للنشر والتوزيع. الأردن.

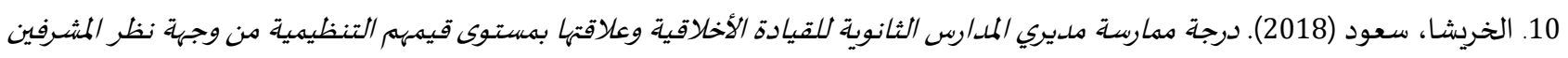

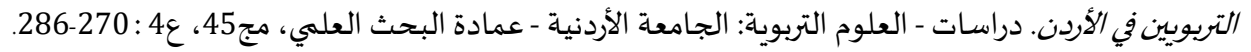

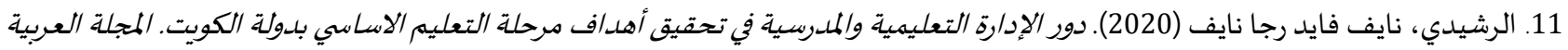

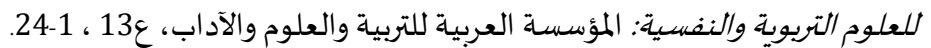

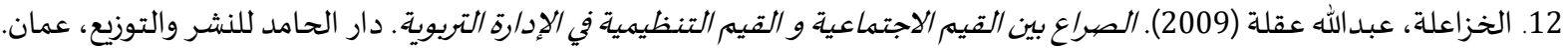

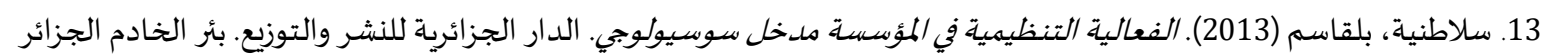
14. عبدالله، نجلاء محمود، وهيئة التحرير (2002). القيم التنظيمية للمديرين في الجهاز الحكومي القطري وعلاقتها بالأداء الوظيفي: دراسة تحليلية .

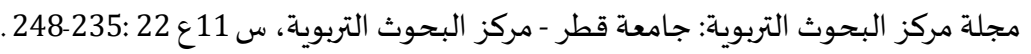
15. عيد، هالة فوزي محمد (2020). تطوير أداء القياد/ت الجامعية في ضيوء تحديات القرن الحادي والعشبرين. المجلة الدولية للبحوث في العلوم

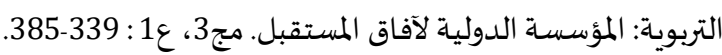

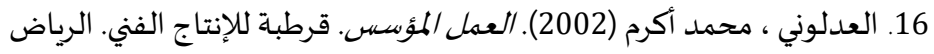

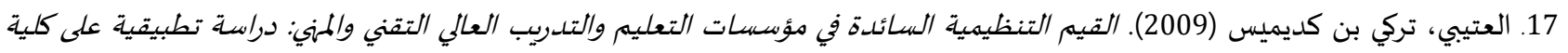

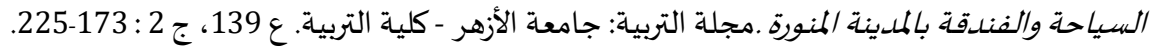

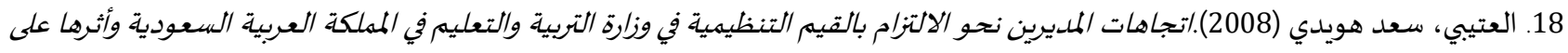
رضاهم الوظيفي. رسالة ماجستير غير منشورة.جامعة مؤتة . الكرك. 19. العتيبي، عبدالله سعد نافع (2019). القيم التنظيمية في الممدرسئ الثانوية الحكومية بمحافظة الطائف وعلاقتها بالالتزام التنظيمي للمعلمين. المجلة التربوية: جامعة سوهاج - كلية التربية، ج66: 186: 483-525. 20. العموش، ضياء احمد عبدالله (2019). أثر القيم التنظيمية في تحسين أداء العاملين في مؤسسة الضهمان الاجتماعي الأردنية. . رسالة ماجستير غير منشورة. جامعة آل البيت، المفرق. 21. العنزي، صالح سلمان سليم (2019). القيم التنظيمية بمدارس محافظة العلا وعلاقتها بالصبراع التنظيمي لدى المعلمين والمعلمات. مجلة كلية

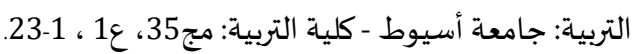

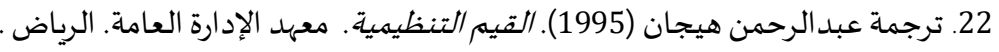
23. فيله، فاروق عبدة، وعبدالحميد، السيد محمد (2008). السلوك التنظيمي في إدارة المؤسسات التعليمية. دار المسيرة للنشر والتوزيع والطباعة. عمان. الأردن. 24. القريوتي، محمد قاسم (1993). دراسة للسلوك الإنساني الفردي والجماعي في المنظمات الإد/رية. ط2 ، مكتبة دار الشروق، عمان الأردن . ثانياً: المراجع الأجنبية:

1. Bourne, H., Jenkins, M., \& Parry, E. (2019). Mapping espoused organizational values. Journal of Business Ethics, 159(1): 133-148, https://doi.org/10.1007/s10551-017-3734-9.

1. Bowden, P. (2000). Delivering organizational excellence by employee values management. Total Quality Management, 11(4-6): 636-640, https://doi.org/10.1080/09544120050007995.

2. francis, D \& woodcock (1990). unblocking organizational values, scott and fores man company, san diego, california.

3. Ortyuand, j. (2006). The relationship between leaders ethics and leadership style. organizational behavior, 3(2):60-86. 


$$
\text { المجلة الدولية للدراسـات التربوية والنفسية }
$$

\title{
Organizational values in government secondary schools in the city of Buraydah from the point of view of teachers
}

\section{Hessa Khalaf Ibrahim Al-adhadh}

Faculty Education, Qassim University, KSA

Hussah.khalaf.1996@hotmail.com

\author{
Received : 15/6/2020 Revised : 22/6/2020 Accepted : 18/7/2020 DOI : https://doi.org/10.31559/EPS2021.9.2.7
}

Abstract: The study aimed to identify the level of organizational values in government secondary schools in the city of Burydah from the viewpoint of female teachers, and to discover whether there are statistically significant differences in the responses of the study sample due to the variables (specialization - years of experience - training courses), and to reach the most important procedural suggestions learned to improve the level of organizational values. The study used the descriptive approach (survey) and was relied on the francis \& woodcock scale, 1995 as a tool to collect information, the study population consisted of 1670 female teachers, and where the primary study sample consisted of 312 female secondary school teachers in Buraydah city, they were chosen in a simple random manner.

The most important results of the study were that the level of organizational values in secondary schools in Buraydah from the information point of view is largely achieved, and came in the first order the main axis (Relationship Management) and its sub-dimensions, and the second (administration administration) with its sub-dimensions, as there are no statistically significant differences in The level of organizational values for female teachers in government secondary schools in Buraydah is due to the difference in years of experience, while there are statistically significant differences in the level of organizational values for female teachers in government secondary schools in Buraydah due to the difference in specialization, and the differences in favor of literary specialties, and the study reached a set of recommendations and proposals was Most notable are the following:

1- Maintaining the full support of female teachers in educational institutions, and creating appropriate organizational conditions for them.

2- Building appropriate training courses to develop skills for workers in educational institutions, especially those dealing with organizational values.

3- Preparing training programs to keep pace with the expected leadership role, in order to establish organizational values.

Keyword: organizational values; secondary schools; Buraydah

\section{References:}

1. 'bdallh, Njla' Mhmwd, Why'h Althryr (2002). Alqym Altnzymyh Llmdyryn Fy Aljhaz Alhkwmy Alqtry W'laqtha Balada' Alwz yfy: Drash Thlylyh. Mjlt Mrkz Albhwth Altrbwyh: Jam't Qtr - Mrkz Albhwth Altrbwyh, S11 ' 22 :235-248.

2. Al'dlwny, Mhmd Akrm (2002). Al'ml Alm'ss. Qrtbh Llentaj Alfny. Alryad.

3. Al'mwsh, Dya' Ahmd 'bdallh (2019). Athr Alqym Altnzymyh Fy Thsyn Ada' Al'amlyn Fy M'sst Aldman Alajtma'y Alardnyh. Rs alt Majstyr Ghyr Mnshwrh. Jam't Al Albyt, Almfrq.

4. Al'nzy, Salh Slman Slym (2019). Alqym Altnzymyh Bmdars Mhafzt Al'la W'laqtha Balsra' Altnzymy Lda Alm'lmyn Walm'lmat . Mjlt Klyt Altrbyh: Jam't Asywt - Klyt Altrbyh: Mj35, '1, 1-23.

5. Al'tyby, 'bdallh S'd Naf' (2019). Alqym Altnzymyh Fy Almdars Althanwyh Alhkwmyh Bmhafzh Alta'f W'laqtha Balaltzam Alt nzymy Llm'Imyn. Almjlh Altrbwyh: Jam't Swhaj - Klyt Altrbyh, J66: 483-525. 
6. Al'tyby, S'd Hwydy (2008). Atjahat Almdyryn Nhw Alaltzam Balqym Altnzymyh Fy Wzarh Altrbyh Walt'lym Fy Almmlkh Al'r byh Als'wdyh Wathrha 'la Rdahm Alwzyfy. Rsalt Majstyr Ghyr Mnshwrh. Jam't M'th Alkrk.

7. Al'tyby, Trky Bn Kdymys (2009). Alqym Altnzymyh Alsa'dh Fy M'ssat Alt'lym Waltdryb Al'aly Altqny Walmhny: Drash Ttbyq yh 'la Klyt Alsyahh Walfndqh Balmdynh Almnwrh. Mjlh Altrbyh: Jam't Alazhr - Klyt Altrbyh. ' 139, J 2: 173-225.

8. 'yd, Halh Fwzy Mhmd (2020). Ttwyr Ada' Alqyadat Aljam'yh Fy Dw' Thdyat Alqrn Alhady Wal'shryn. Almjlh Aldwlyh Llbhwt h Fy Al'lwm Altrbwyh: Alm'ssh Aldwlyh Lafaq Almstqbl. Mj3, '1: 339-385.

9. Alb'dany, 'bdalmlk Mhmd Mlhy (2017). Dwr Akhlaqyat Al'ml Walqym Altnzymyh Fy Alrda Walada' Alwzyfy Ll'amlyn: Drash Ttbyqyh Fy Almstshfyat Alkhash Fy Al'asmh Alymnyh Sn'a'. Rsalt Dktwrah. Jam't Alnylyn, Alkhrtwm,

10. Ban'mh, Fwzyh Bnt 'bdalrhmn Salm (2012). Alqym Altnzymyh Almhfzh Llebda' Aladary Lda Mdyrat Mdars Alt'lym Althanw y Al'am Alhkwmy Walahly Bmdynt Mkh Almkrmh. Drasat 'rbyh Fy Altrbyh W'lm Alnfs: Rabth Altrbwyyn Al'rb, '24: J1, 289-3 30 .

11. Bn Hamd, 'adl (2017). Alqym Altnzymyh Wan'kasha 'la Jwdh Alt'lym Al'aly: Drash Mshyh Llasatdh Albahthyn Fy 'lm Alajtma ' Bjam't Qasdy Mrbah Wrqlh. Rsalt Majstyr Ghyr Mnshwrh. Jam't Qasdy Mrbah - Wrqlh, Wrqlh.

12. Bwdhry W'bd Alrhmn (2018). Alqym Altnzymyh W'laqtha Bmstwa Alaltzam Altnzymy Drash Mydanyh 'la 'ynh Mn 'mal M'ss t" Hybrwk.

13. Bwqraf, Alms'wd, Dwmh, 'bd Alqadr (2017). Alqym Altnzymyh W'laqtha Balaltzam Altnzym.

14. Fylh, Farwq 'bdh, W'bdalhmyd, Alsyd Mhmd (2008). Alslwk Altnzymy Fy Edart Alm'ssat Alt'lymyh. Dar Almsyrh Llnshr Walt wzy' Waltba'h. 'man. Alardn.

15. Aljabr, Ltyfh Bnt Ebrahym Bn Mhmd (2019). Alqym Altnzymyh W'laqtha Baltsrb Alwzyfy Mn Wjht Nzr A'da' Hy't Altdryb B m'hd Aledarh Al'amh. Almjlh Al'erbyh Lledarh: Almnzmh Al'rbyh Lltnmyh Aledaryh: Mj39,'3: 53-77.

16. Aljlad, Majd Zky (2005). T'Im Alqym Wt'lymha. T2, Dar Almsyrh Llnshr Waltwzy'. Alardn.

17. Alkhrysha, S'wd (2018). Drjt Mmarst Mdyry Almdars Althanwyh Llqyadh Alakhlaqyh W'laqtha Bmstwa Qymhm Altnzymyh Mn Wjht Nzr Almshrfyn Altrbwyyn Fy Alardn. Drasat - Al'lwm Altrbwyh: Aljam'h Alardnyh - 'madt Albhth Al'lmy, Mj45, '4: 2 70-286.

18. Alkhza'lh, 'bdallh 'Eqlh (2009). Alsra' Byn Alqym Alajtma'yh W Alqym Altnzymyh Fy Aledarh Altrbwyh. Dar Alhamd Llnshr Waltwzy', 'man.

19. Alqrywty, Mhmd Qasm (1993). Drash Llslwk Alensany Alfrdy Waljma'y Fy Almnzmat Aledaryh. T2, Mktbt Dar Alshrwq, 'ma n Alardn.

20. Alrshydy, Nayf Fayd Rja Nayf (2020). Dwr Aledarh Alt'lymyh Walmdrsyh Fy Thqyq Ahdaf Mrhlt Alt'lym Alasasy Bdwlh Alkw yt. Almjlh Al'rbyh Ll'lwm Altrbwyh Walnfsyh: Alm'ssh Al'rbyh Lltrbyh Wal'lwm Waladab, '13, 1-24.

21. Slatnyh, Blqasm (2013). Alf'alyh Altnzymyh Fy Alm'ssh Mdkhl Swsywlwjy. Aldar Aljza'eryh Llnshr Waltwzy'. B'r Alkhadm Al jza'r.

22. Altlbany, Nhayh, Fars, Mhmd Jwdt, Walwhydy, Raf'e Ywsf (2015). Alqym Altnzymyh W'laqtha Balanghmas Alwzyfy: Drash M ydanyh 'la Mwzfy Albnwk Aleslamyh/ Qta' Ghzh. Mjlt Jam't Alqds Almftwhh Llbhwth Aledaryh Walaqtsadyh: Jam't Alqds Al mftwhh. Mj1,'2: 49.

23. Trjmt 'bdalrhmn Hyjan (1995). Alqym Altnzymyh. M'hd Aledarh Al'amh. Alryad.

24. Altwyjr, Ans Mhmd (2001). Waq' Alqym Alshkhsyh Waltnzymyh Wathrha Fy Fa'lyt Almdyryn Fy Alwzarat Alardnyh. Rsalt M ajstyr Ghyr Mnshwrh. Jam't M'th, Alardn. 